ORNL/TM-2000/4

\title{
Analyses of Weapons-Grade MOX VVER-1000 Neutronics Benchmarks: Pin-Cell Calculations with SCALE/SAS2H
}

\author{
R. J. Ellis
}

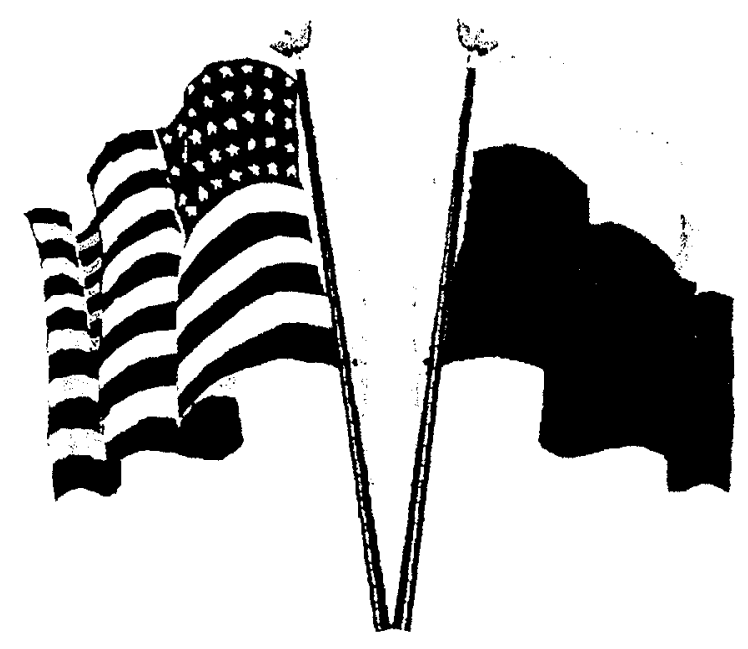

FISSILE MATERIALS DISPOSITION PROGRAM 
Page Intentionally Blank 


\section{CONTENTS}

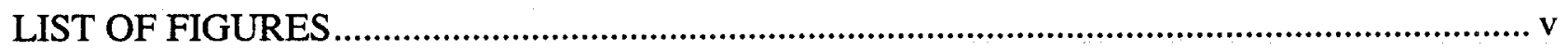

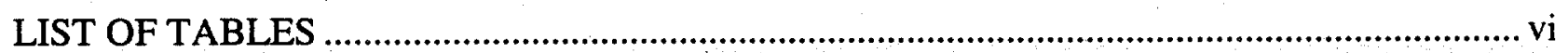

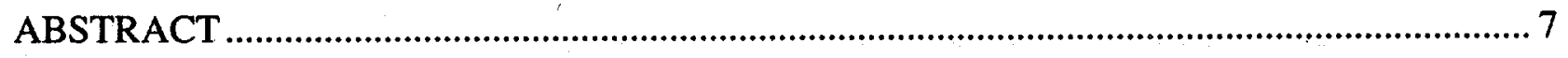

1 INTRODUCTION

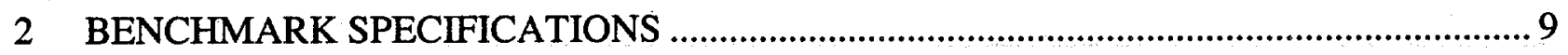

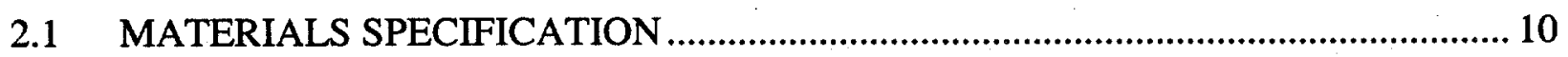

2.2 DESCRIPTION OF GEOMETRY .................................................................... 11

2.3 BENCHMARK FUEL VARIANTS ....................................................................... 12

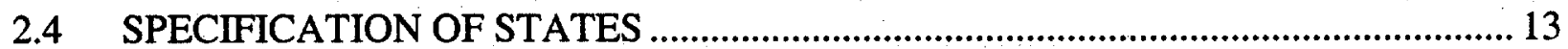

2.5 PARAMETERS CALCULATED IN THE BENCHMARK .......................................... 13

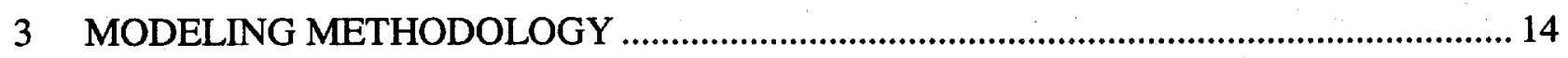

3.1 THE SCALE-4.3/SAS2H CODE - USED IN THIS STUDY...................................... 14

3.2 DESCRIPTION OF MODELING CODES USED IN OTHER STUDIES ..................... 16

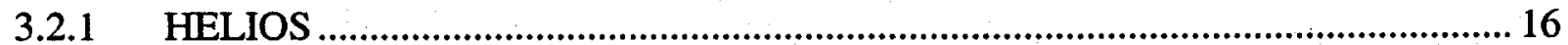

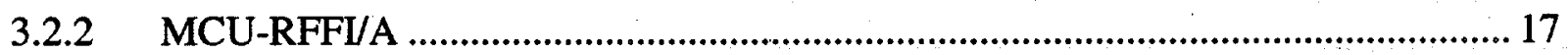

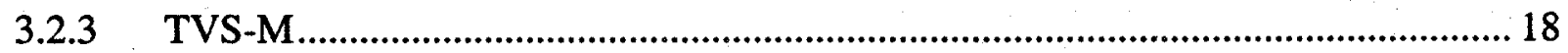

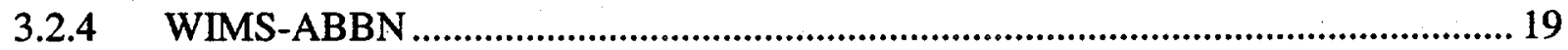

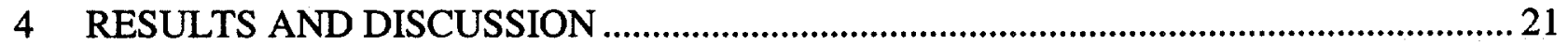

4.1 BENCHMARK RESULTS FOR CASES WITHOUT FUEL DEPLETION …………..... 21

4.2 BENCHMARK RESULTS FOR CASES WITH FUEL DEPLETION ............................2 27

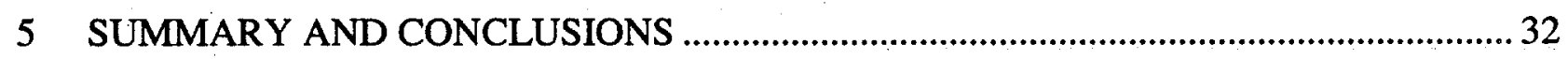

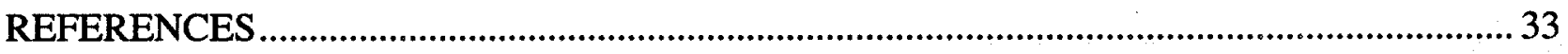

APPENDIX A. SAMPLE SAS2H INPUT DATA FILE - CASE V1, S1 (LEU UO $\left.{ }_{2}\right) \ldots \ldots \ldots \ldots . . . . . .34$

APPENDIX B. SAMPLE SAS2H INPUT DATA FILE - CASE V2, S1 (WG MOX) ...............36

APPENDIX C. SAMPLE SAS2H INPUT DATA FILE - CASE V10, S1 (RG MOX) ...............38

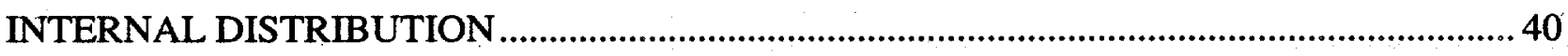

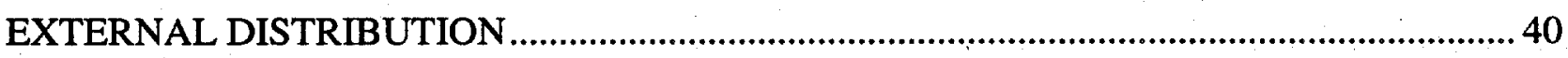




\section{Page Intentionally Blank}




\section{LIST OF FIGURES}

Figure 2.1. VVER-1000 neutronics benchmark pin-cell model. ....................................................11 Figure 4.1. $\mathrm{k}_{\mathrm{o}}$ for $\mathrm{V} 1, \mathrm{~V} 2$, and $\mathrm{V} 10$ at fresh (BOL) and 60MWd/kgHE (EOL) burnup............... 28

Figure 4.2. Code Comparison of $k_{0}$ vs burnup for Fuel Variant V2 (WG MOX)........................2 29

Figure 4.3. Code Comparison of $k_{o}$ vs burnup for Fuel Variant V10 (RG MOX).......................... 31 


\section{LIST OF TABLES}

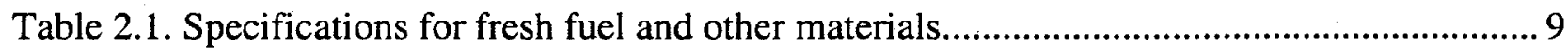

Table 2.2. Specifications for spent fuel materials. .................................................................. 10

Table 2.3. Summary of the benchmark variant fuel materials. ......................................................... 12

Table 2.4. Definition of the states used in the pin-cell benchmark scenarios............................... 13

Table 4.1. SCALE-4.3/SAS2H zero-burnup benchmark results: V1-V10, states S1-S6............... 23

Table 4.2. Benchmark case k-values by variant, state, and computer code.................................2 24

Table 4.3. Reactivity differences between SAS2H and HELIOS k-values results.........................2.27

Table 4.4. Reactivity effects by fuel variant, state changes, and computer code............................ 28

Table 4.5. Comparison of $\mathrm{k}_{\mathrm{eff}}$ and $\mathrm{k}_{\mathrm{o}}$ calculations in state $\mathrm{S} 1$ fuel depletion simulations. ............ 27

Table 4.6. ${ }^{135} \mathrm{Xe}$ concentration $(\mathrm{a} / \mathrm{b}-\mathrm{cm})$ in fuel during depletion simulation for $\mathrm{V} 2$. .................... 30

Table 4.7. ${ }^{149} \mathrm{Sm}$ concentration $(\mathrm{a} / \mathrm{b}-\mathrm{cm})$ in fuel during depletion simulation for $\mathrm{V} 2$.....................30

Table 4.8. ${ }^{239} \mathrm{Pu}$ concentration $(\mathrm{a} / \mathrm{b}-\mathrm{cm})$ in fuel during depletion simulation for $\mathrm{V} 2$...................... 30

Table 4.9. ${ }^{235} \mathrm{U}$ concentration $(\mathrm{a} / \mathrm{b}-\mathrm{cm})$ in fuel during depletion simulation for $\mathrm{V} 2$. ..................... 30 


\begin{abstract}
A series of unit pin-cell benchmark problems have been analyzed related to irradiation of mixed oxide fuel in VVER-1000s ("water-water energetic reactors"). Onedimensional, discrete-ordinates eigenvalue calculations of these benchmarks were performed at ORNL using the SAS2H control sequence module of the SCALE-4.3 computational code system, as part of the Fissile Materials Disposition Program (FMDP) of the US DOE. Calculations were also performed using the SCALE module CSAS to confirm the results. The 238 neutron energy group SCALE nuclear data library 238GROUPNDF5 (based on ENDF/B-V) was used for all calculations. The VVER-1000 pin-cell benchmark cases modeled with SAS2H included zero-burnup calculations for eight fuel material variants (from $\mathrm{LEU} \mathrm{UO}_{2}$ to weapons-grade $\mathrm{MOX}$ ) at five different reactor states, and three fuel depletion cases up to high burnup. Results of the SAS2H analyses of the VVER-1000 neutronics benchmarks are presented in this report. Good general agreement was obtained between the SAS2H results, the ORNL results using HELIOS-1.4 with ENDF/B-VI nuclear data, and the results from several Russian benchmark studies using the codes TVS-M, MCU-RFFI/A, and WIMS-ABBN. This SAS2H benchmark study is useful for the verification of HELIOS calculations, the HELIOS code being the principal computational tool at ORNL for physics studies of assembly design for weapons-grade plutonium disposition in Russian reactors.
\end{abstract}




\section{INTRODUCTION}

Part of the effort to eliminate surplus weapons-grade plutonium is to assess the options for burning the fuel material in commercial power reactors. In the Russian Federation, a prime candidate for plutonium disposition is the VVER-1000 class of reactors. Benchmarking is necessary to confirm that our calculational methods and nuclear data libraries can accurately model VVER-1000 reactors with MOX fuel on high-grade plutonium (i.e., $>90 \mathrm{wt} \%{ }^{239} \mathrm{Pu}$ ).

Recently, a number of computational and experimental benchmarks were analyzed in Russia ${ }^{1}$. The computational benchmarks were designed to allow detailed comparisons of calculational methods and nuclear data used in the computer code systems. The various VVER-1000 benchmark cases represent many variations in fuel materials and reactor conditions.

This report documents the calculational results for benchmark cases using the SAS2H sequence module of the SCALE ${ }^{2}$ code system. SAS2H was used for all the pincell benchmark case analyses because it could be used for both zero-burnup and fuel

depletion cases. The final SCALE/SAS2H results are compared to the ORNL results ${ }^{3}$ with the HELIOS ${ }^{4,5}$ code and the results of the Russian codes MCU-RFFI/A ${ }^{1}$, TVS-M ${ }^{1,6}$, and WIMS-ABBN ${ }^{1}$. The comparison of the SAS2H results to the results of the other codes is not an exhaustive comparison and is done for illustrative purposes. Only the Russian results from Reference 1 were used in any comparison. There have been subsequent new Russian benchmark results but new inter-code results comparisons will be made elsewhere.

This study also serves to confirm and verify the HELIOS calculations; this is important since HELIOS is the main computational code used in our physics assessments of assembly designs for Pu disposition in Russian VVER-1000 reactors.

The benchmark cases analyzed in this work with SAS2H represent a major subset of the entire VVER-1000 neutronics benchmark case specifications. A total of 83 SAS2H pin-cell cases were simulated during this work. Eight fuel variants were modeled in these cases ranging from $\mathrm{LEU} \mathrm{UO}_{2}$ to weapons and reactor-grade MOX fuel, with a variety of fuel isotopic inventories. The various pin-cells were analyzed for different states of reactor conditions such as fuel temperature and moderator temperature and density. These states are representative of normal operational conditions for VVER-1000 reactors and certain off-operation conditions. Three of the pin-cell benchmark cases analyzed simulated fuel depletion up to a burnup of $60 \mathrm{MWd} / \mathrm{kgHE}$ (Mega Watt days per $\underline{\mathrm{kg}}$ of Heavy Elements).

The benchmark case specifications used for the SAS2H calculations are presented in Section 2. The modeling methodology employed with the SCALE/SAS2H sequence and an introduction and description of the other codes used in the VVER-1000 benchmark in the US and in Russia are discussed in Section 3. The calculational results and observations from this work are presented and discussed in Section 4 for both zeroburnup benchmark cases and several fuel depletion benchmark simulations. The findings of the benchmark study are summarized in Section 5. 


\section{BENCHMARK SPECIFICATIONS}

The VVER-1000 benchmark case specifications are presented in Reference 1. The cases simulated with SAS2H are pin-cell calculations for a variety of fuel materials ranging from $\mathrm{LEU} \mathrm{UO}_{2}$ to $\mathrm{MOX}$ fuel with reactor-grade plutonium and with weaponsgrade plutonium. The various fuel compositions are referred to as fuel variants; for this work, eight fuel variants V1-V4 and V7-V10 were modeled. The benchmark case simulations were performed for five specific sets of reactor conditions (States S1 to S6) which represent normal and off-normal situations including specified values for fuel temperatures, moderator temperature and density, fission product poison concentrations, moderator boron level. Three representative SCALE-4.3 SAS2H input data files for the fuel depletion pin-cell benchmarks are attached to this report as Appendices A to C.

Table 2.1. Specifications for fresh fuel and other materials.

\begin{tabular}{|c|c|c|c|c|c|}
\hline Material & Comment & Nuclide & $\begin{array}{l}\text { Content } \\
(\mathrm{a} / \mathrm{b}-\mathrm{cm})\end{array}$ & Nuclide & $\begin{array}{l}\text { Content } \\
(\mathrm{a} / \mathrm{b}-\mathrm{cm})\end{array}$ \\
\hline FU1 & Fresh uranium fuel & ${ }^{235} \mathrm{U}$ & $\begin{array}{l}8.7370 \times 10^{-4} \\
1.8744 \times 10^{-2}\end{array}$ & ${ }^{16} \mathrm{O}$ & $3.9235 \times 10^{-2}$ \\
\hline FU2 & Fresh MOX fuel (WG Pu) & $\begin{array}{c}{ }^{235} \mathrm{U} \\
{ }^{238} \mathrm{U} \\
{ }^{16} \mathrm{O}\end{array}$ & $\begin{array}{l}3.8393 \times 10^{-5} \\
1.8917 \times 10^{-2} \\
4.1707 \times 10^{-2}\end{array}$ & $\begin{array}{l}{ }^{239} \mathrm{Pu} \\
{ }^{240} \mathrm{Pu} \\
{ }^{241} \mathrm{Pu}\end{array}$ & $\begin{array}{l}6.5875 \times 10^{-4} \\
4.2323 \times 10^{-5} \\
7.0246 \times 10^{-6}\end{array}$ \\
\hline FU7 & MOX fuel with ${ }^{239} \mathrm{Pu}$ only & ${ }^{235} \mathrm{U}$ & $\begin{array}{l}3.8393 \times 10^{-5} \\
1.8917 \times 10^{-2}\end{array}$ & $\begin{array}{l}{ }^{239} \mathrm{Pu} \\
{ }^{16} \mathrm{O} \\
\end{array}$ & $\begin{array}{l}6.5875 \times 10^{-4} \\
4.1707 \times 10^{-4} \\
\end{array}$ \\
\hline FU8 & MOX fuel with ${ }^{240} \mathrm{Pu}$ only & ${ }^{235} \mathrm{U}$ & $\begin{array}{l}6.9714 \times 10^{-4} \\
1.8917 \times 10^{-2}\end{array}$ & $\begin{array}{l}{ }^{240} \mathrm{Pu} \\
{ }^{16} \mathrm{O}\end{array}$ & $\begin{array}{l}4.2323 \times 10^{-5} \\
4.1707 \times 10^{-2}\end{array}$ \\
\hline FU9 & MOX fuel with ${ }^{241} \mathrm{Pu}$ only & ${ }^{235} \mathrm{U}$ & $\begin{array}{l}3.8393 \times 10^{-5} \\
1.8917 \times 10^{-2}\end{array}$ & $\begin{array}{l}{ }^{24 !} \mathrm{Pu} \\
{ }^{16} \mathrm{O} \\
\end{array}$ & $\begin{array}{l}6.6577 \times 10^{-4} \\
4.1707 \times 10^{-2}\end{array}$ \\
\hline FU10 & Fresh MOX fuel (RG Pu) & $\begin{array}{c}{ }^{235} \mathrm{U} \\
{ }^{238} \mathrm{U} \\
{ }^{16} \mathrm{O} \\
{ }^{238} \mathrm{Pu} \\
{ }^{239} \mathrm{Pu} \\
\end{array}$ & $\begin{array}{l}5.0000 \times 10^{-5} \\
2.2100 \times 10^{-2} \\
4.6300 \times 10^{-2} \\
3.0000 \times 10^{-5} \\
1.1600 \times 10^{-3}\end{array}$ & $\begin{array}{l}{ }^{240} \mathrm{Pu} \\
{ }^{241} \mathrm{Pu} \\
{ }^{242} \mathrm{Pu} \\
{ }^{241} \mathrm{Am}\end{array}$ & $\begin{array}{l}4.9000 \times 10^{-4} \\
1.9000 \times 10^{-4} \\
1.0500 \times 10^{-4} \\
2.5000 \times 10^{-5}\end{array}$ \\
\hline CL1 & Cladding & $\mathrm{Zr}$ & $4.2300 \times 10^{-2}$ & & \\
\hline MOD1 & Hot moderator with boron acid & $\begin{array}{c}\mathrm{H} \\
{ }^{16} \mathrm{O}\end{array}$ & $\begin{array}{l}4.783 \times 10^{-2} \\
2.391 \times 10^{-2}\end{array}$ & $\begin{array}{l}{ }^{10} \mathrm{~B} \\
{ }^{11} \mathrm{~B}\end{array}$ & $\begin{array}{l}4.7344 \times 10^{-6} \\
1.9177 \times 10^{-5}\end{array}$ \\
\hline MOD2 & $\begin{array}{l}\text { Hot moderator without boron } \\
\text { acid }\end{array}$ & $\mathbf{H}$ & $4.783 \times 10^{-2}$ & ${ }^{16} \mathrm{O}$ & $2.391 \times 10^{-2}$ \\
\hline MOD3 & Cold moderator with boron acid & $\begin{array}{c}\mathrm{H} \\
{ }^{16} \mathrm{O}\end{array}$ & $\begin{array}{l}6.694 \times 10^{-2} \\
3.347 \times 10^{-2}\end{array}$ & $\begin{array}{l}{ }^{10} \mathrm{~B} \\
{ }^{11} \mathrm{~B}\end{array}$ & $\begin{array}{l}6.6262 \times 10^{-6} \\
2.6839 \times 10^{-5}\end{array}$ \\
\hline
\end{tabular}




\subsection{MATERIALS SPECIFICATION}

Material specifications from Reference 1 for the various fuel compositions with fresh fuel (FU1, FU2, FU7-FU10) are given in Table 2.1 and the spent fuel material specifications (FU3, FU4) are given in Table 2.2. Table 2.1 also presents the material compositions of the zirconium cladding and three different states of the light-water moderator.

Table 2.2. Specifications for spent fuel materials.

\begin{tabular}{|c|c|c|c|c|c|}
\hline Material & Comment & Nuclide & $\begin{array}{l}\text { Content } \\
(\mathrm{a} / \mathrm{b}-\mathrm{cm})\end{array}$ & Nuclide & $\begin{array}{l}\text { Content } \\
(\mathrm{a} / \mathrm{b}-\mathrm{cm})\end{array}$ \\
\hline FU3 & Spent uranium fuel without FPs & $\begin{array}{l}{ }^{235} \mathrm{U} \\
{ }^{236} \mathrm{U} \\
{ }^{238} \mathrm{U} \\
{ }^{237} \mathrm{~Np} \\
{ }^{238} \mathrm{Pu} \\
{ }^{239} \mathrm{~Np} \\
{ }^{239} \mathrm{Pu} \\
{ }^{240} \mathrm{Pu} \\
{ }^{241} \mathrm{Pu}\end{array}$ & $\begin{array}{l}3.78430 \times 10^{-4} \\
8.63650 \times 10^{-5} \\
1.83270 \times 10^{-2} \\
2.48230 \times 10^{-5} \\
6.72540 \times 10^{-6} \\
1.83320 \times 10^{-6} \\
1.31110 \times 10^{-4} \\
3.62330 \times 10^{-5} \\
2.17010 \times 10^{-5} \\
\end{array}$ & $\begin{array}{l}{ }^{242} \mathrm{Pu} \\
{ }^{241} \mathrm{Am} \\
{ }^{242 \mathrm{~m}} \mathrm{Am} \\
{ }^{243} \mathrm{Am} \\
{ }^{242} \mathrm{Cm} \\
{ }^{243} \mathrm{Cm} \\
{ }^{244} \mathrm{Cm} \\
{ }^{16} \mathrm{O}\end{array}$ & $\begin{array}{l}4.75760 \times 10^{-6} \\
4.94910 \times 10^{-7} \\
7.91940 \times 10^{-9} \\
6.69250 \times 10^{-7} \\
1.25820 \times 10^{-7} \\
2.06290 \times 10^{-9} \\
1.23870 \times 10^{-7} \\
3.9235 \times 10^{-2}\end{array}$ \\
\hline FU4 & Spent uranium fuel with FPs & $\begin{array}{l}{ }^{235} \mathrm{U} \\
{ }^{236} \mathrm{U} \\
{ }^{238} \mathrm{U} \\
{ }^{237} \mathrm{~Np} \\
{ }^{238} \mathrm{Pu} \\
{ }^{239} \mathrm{~Np} \\
{ }^{239} \mathrm{Pu} \\
{ }^{240} \mathrm{Pu} \\
{ }^{241} \mathrm{Pu} \\
{ }^{103} \mathrm{Rh} \\
{ }^{131} \mathrm{Xe} \\
{ }^{143} \mathrm{Nd} \\
{ }^{147} \mathrm{Pm} \\
{ }^{133} \mathrm{Cs} \\
{ }^{99} \mathrm{Tc} \\
{ }^{152} \mathrm{Sm} \\
{ }^{151} \mathrm{Sm}\end{array}$ & $\begin{array}{l}3.78430 \times 10^{-4} \\
8.63650 \times 10^{-5} \\
1.83270 \times 10^{-2} \\
2.48230 \times 10^{-5} \\
6.72540 \times 10^{-6} \\
1.83320 \times 10^{-6} \\
1.31110 \times 10^{-4} \\
3.62330 \times 10^{-5} \\
2.17010 \times 10^{-5} \\
1.8890 \times 10^{-5} \\
1.4255 \times 10^{-5} \\
2.6692 \times 10^{-5} \\
6.1574 \times 10^{-6} \\
3.5974 \times 10^{-5} \\
3.3320 \times 10^{-5} \\
2.6842 \times 10^{-6} \\
3.0757 \times 10^{-7}\end{array}$ & $\begin{array}{l}{ }^{242} \mathrm{Pu} \\
{ }^{241} \mathrm{Am} \\
{ }^{242 \mathrm{~m}} \mathrm{Am} \\
{ }^{243} \mathrm{Am} \\
{ }^{242} \mathrm{Cm} \\
{ }^{243} \mathrm{Cm} \\
{ }^{244} \mathrm{Cm} \\
{ }^{16} \mathrm{O} \\
{ }^{145} \mathrm{Nd} \\
{ }^{153} \mathrm{Eu} \\
{ }^{109} \mathrm{Ag} \\
{ }^{155} \mathrm{Eu} \\
{ }^{95} \mathrm{Mo} \\
{ }^{154} \mathrm{Eu} \\
{ }^{101} \mathrm{Ru}\end{array}$ & $\begin{array}{l}4.75760 \times 10^{-6} \\
4.94910 \times 10^{-7} \\
7.91940 \times 10^{-9} \\
6.69250 \times 10^{-7} \\
1.25820 \times 10^{-7} \\
2.06290 \times 10^{-9} \\
1.23870 \times 10^{-7} \\
3.9235 \times 10^{-2} \\
1.9975 \times 10^{-5} \\
2.4801 \times 10^{-6} \\
2.2037 \times 10^{-6} \\
9.6857 \times 10^{-8} \\
3.3720 \times 10^{-5} \\
5.1189 \times 10^{-7} \\
3.1134 \times 10^{-5}\end{array}$ \\
\hline
\end{tabular}

Three of the fuel materials (FU7, FU8, FU9) are special mixtures of fresh MOX fuel with only one individual plutonium isotope $\left({ }^{239} \mathrm{Pu},{ }^{240} \mathrm{Pu}\right.$, and ${ }^{241} \mathrm{Pu}$, respectively). These unusual isotopic compositions are included in the benchmark cases to allow for the assessment of the effects of each individual major plutonium isotope. The cladding 
material (CL1) for all the benchmark cases is natural zirconium. The moderator materials used in the benchmark cases (MOD1, MOD2, MOD3) represent different densities and boron concentrations, from dissolved boron acid, in light water. MOD1 and MOD2 are hot light water with and without boron in the moderator, respectively. MOD3 is cold light water with dissolved boron.

\subsection{DESCRIPTION OF GEOMETRY}

In the actual VVER-1000 reactor fuel assemblies, the fuel pins have a central hole, and the fuel is arranged on a hexagonal (triangular) pitch in hexagonal fuel assemblies. For the purposes of the VVER-1000 pin-cell benchmark studies, the specifications from Reference 1 call for pin-cell models with an hexagonal pitch of $1.275 \mathrm{~cm}$. The diameter of the cylindrical fuel region is given as $0.772 \mathrm{~cm}$. For simplicity of modeling, the

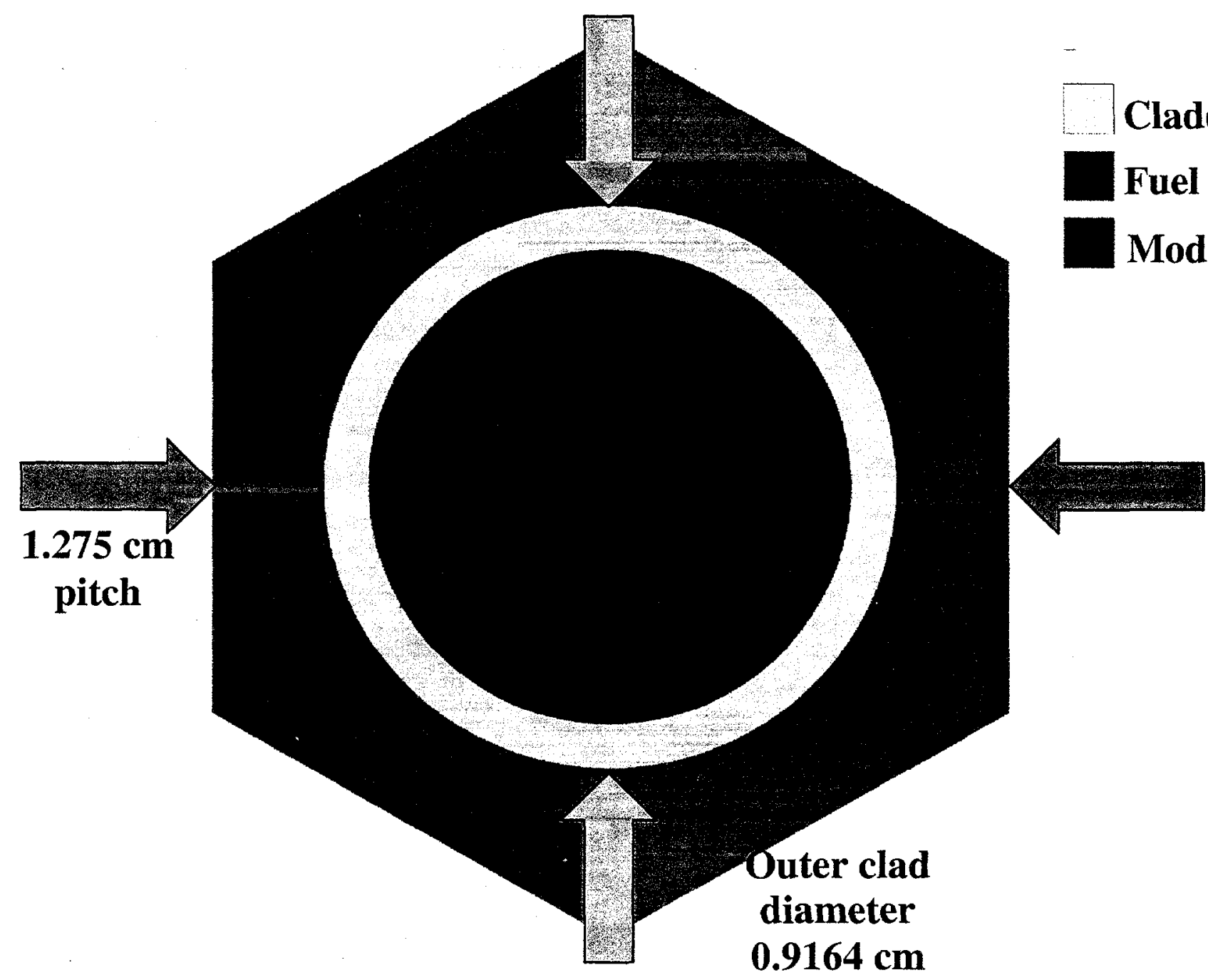

Figure 2.1. VVER-1000 neutronics benchmark pin-cell model. 
central hole in the fuel pellet is not included in the benchmark. The cladding outer diameter is given as $0.9164 \mathrm{~cm}$, for a cladding thickness of $0.0772 \mathrm{~cm}$. All the calculations were performed using a buckling value $\mathrm{B}^{2}=0.003 \mathrm{~cm}^{-2}$ to represent the neutron leakage for the fuel types in the critical reactor.

\subsection{BENCHMARK FUEL VARIANTS}

The benchmark variant numbers V1-V10 discussed in this report are in coincidence with the fuel material numbers FU1-FU10. However, the benchmark variants V1-V4 and V7-V10 analyzed for this pin-cell study are actually combinations of the fuel materials, reactor conditions, and state specifications. The pin-cell variant benchmark cases were performed for the same pin-cell geometry.

The spatial power density (thermal power per volume) for the core region for all the cases is specified in Reference 1 as $108 \mathrm{MW} / \mathrm{m}^{3}$. For the fuel variant materials, the specific power levels (thermal power per mass of heavy elements) for each fuel composition differ in order to meet the constraint of constant power density of 108

$\mathrm{MW} / \mathrm{m}^{3}$. Table 2.3 indicates the values of the specific power level used in each SAS2H benchmark variant simulation.

Table 2.3. Summary of the benchmark variant fuel materials.

\begin{tabular}{ccccc}
\hline $\begin{array}{c}\text { Benchmark } \\
\text { variant }\end{array}$ & $\begin{array}{c}\text { Fuel material } \\
\text { name }\end{array}$ & $\begin{array}{c}\text { General description of fuel } \\
\text { composition }\end{array}$ & $\begin{array}{c}\text { "length" of } \\
\text { fuel pin to } \\
\text { contain } 1 \mathrm{~kg} \text { of } \\
\text { heavy } \\
\text { elements (cm) }\end{array}$ & $\begin{array}{c}\text { Specific Power } \\
\text { Density } \\
\text { (kW/kgHE) }\end{array}$ \\
\hline V1 & FU1 & LEU UO 2 & 275.643 & 41.9107 \\
V2 & FU2 & Weapons-Grade MOX & 274.826 & 41.7837 \\
V3 & FU3 & Spent LEU without Fission Products & 284.204 & 43.2124 \\
V4 & FU4 & Spent LEU with Fission Products & 284.204 & 43.2124 \\
V7 & FU7 & MOX with only ${ }^{239} \mathrm{Pu}$ & 275.505 & 41.8898 \\
V8 & FU8 & MOX with only ${ }^{240} \mathrm{Pu}$ & 275.063 & 41.8225 \\
V9 & FU9 & MOX with only ${ }^{241} \mathrm{Pu}$ & 275.330 & 41.8628 \\
V10 & FU10 & Reactor-Grade MOX & 223.667 & 34.0078 \\
\hline
\end{tabular}

The appropriate power density values were used in the SAS2H case inputs (see Appendices A to C) on the basis of MW per "volume of interest"; for these cases, the "volume of interest" was the length of a fuel pin (also tabulated in Table 2.3) that would contain exactly $1 \mathrm{~kg}$ of heavy elements (U, Pu, etc.). However, the power density and fuel volume for $1 \mathrm{~kg}$ of heavy elements are necessary only for normalization for the three benchmark fuel depletion cases (V1, V2, and V10; in State S1). 


\subsection{SPECIFICATION OF STATES}

The SCALE/SAS2H benchmark calculations were performed for a variety of state conditions for each of the various fuel variant material compositions. The state conditions are tabulated in Table 2.4 and these represent a number of fuel and non-fuel temperatures, different moderator conditions and materials, and different ${ }^{135} \mathrm{Xe}$ and ${ }^{149} \mathrm{Sm}$ concentrations. These state specifications are typical of the conditions and materials in VVER-1000 reactors during operation (S1-S4), and also off-operation conditions (S5) and during shutdown situations or zero-power operation (S6).

Table 2.4. Definition of the states used in the pin-cell benchmark scenarios.

\begin{tabular}{|c|c|c|c|c|}
\hline State & $\begin{array}{c}\text { Temperature of } \\
\text { the fuel } \\
\text { material }(\mathrm{K})\end{array}$ & $\begin{array}{l}\text { Temperature of } \\
\text { the non-fuel } \\
\text { components (K) }\end{array}$ & Moderator & $\begin{array}{c}\text { Initial } \\
\text { specification of } \\
{ }^{135} \mathrm{Xe} \text { and }{ }^{149} \mathrm{Sm} \\
\text { concentration }\end{array}$ \\
\hline S1 & 1027 & 579 & $\begin{array}{c}\text { (Hot) light } \\
\text { water, } \\
\text { dissolved B, } \\
579 \mathrm{~K}\end{array}$ & $\begin{array}{l}\text { Given values [1] } \\
\text { (a/b-cm) for } \\
\text { "Equilibrium } \\
\text { concentrations": } \\
{ }^{135} \mathrm{Xe:} 9.4581 \times 10^{-9} \\
{ }^{149} \mathrm{Sm}: 7.3667 \times 10^{-8}\end{array}$ \\
\hline S3 & 1027 & 579 & $\begin{array}{c}\text { (Hot) light } \\
\text { water, no } \\
\text { dissolved B, } \\
\text { 579K }\end{array}$ & $\begin{array}{l}\text { Given values [1] } \\
\text { (a/b-cm) for } \\
\text { "Equilibrium } \\
\text { concentrations": } \\
{ }^{135} \mathrm{Xe}: 9.4581 \times 10^{-9} \\
{ }^{149} \mathrm{Sm}: 7.3667 \times 10^{-8}\end{array}$ \\
\hline S4 & 1027 & 579 & $\begin{array}{c}\text { (Hot) light } \\
\text { water, } \\
\text { dissolved } \mathrm{B} \text {, } \\
579 \mathrm{~K}\end{array}$ & None \\
\hline S5 & 579 & 579 & $\begin{array}{c}\text { (Hot) light } \\
\text { water, } \\
\text { dissolved } \mathrm{B} \text {, } \\
579 \mathrm{~K}\end{array}$ & None \\
\hline S6 & 300 & 300 & $\begin{array}{c}\text { Cold) light } \\
\text { water, } \\
\text { dissolved } \mathrm{B}, \\
300 \mathrm{~K} \\
\end{array}$ & None \\
\hline
\end{tabular}

\subsection{PARAMETERS CALCULATED IN THE BENCHMARK}

The parameters of importance that were calculated and used during the SCALE-4.3/SAS2H benchmark study include $\mathrm{k}_{\text {eff, }} \mathrm{k}_{\mathbf{0}}, \mathrm{k}_{\text {inf, isotopic concentrations of }}$ actinide and fission product nuclides, and the depletion behavior ( 0 to $60 \mathrm{MWd} / \mathrm{kgHE}$ in burnup steps of $2 \mathrm{MWd} / \mathrm{kgHE}$ ) for selected cases. The definition of the $\mathrm{k}_{\mathrm{o}}$ factor is the infinite multiplication factor of the system, the ratio of total neutron production to the total neutron absorption, in the critical spectrum. 


\section{MODELING METHODOLOGY}

In this section, some of the main details and description are presented about the SCALE/SAS2H code sequence used to simulate the VVER-1000 neutronics pin-cell benchmark cases. A brief introduction and summary is then presented about other computer codes used to analyze the benchmark cases. Later in this report, some of these other benchmark results are compared to the SAS2H pin-cell benchmark results. A schematic of the actual hexagonal pin-cell geometry modeled for the VVER-1000 neutronics benchmark is portrayed in Figure 3.1.

\subsection{THE SCALE-4.3/SAS2H CODE - USED IN THIS STUDY}

The benchmark cases were simulated based on discrete ordinates theory using the SAS2H sequence of the SCALE 4.3 code package. In order to obtain the various $\mathrm{k}$-values for the zero-burnup (non-depletion) cases, two cases were actually calculated: one with the buckling height entered in the input, and the other with no buckling. The latter yields the appropriate $\mathrm{k}_{\mathrm{inf}}$. The case with the buckling height entered yields the value for $k_{\text {eff }}$ and for $k_{0}$. A total of 80 non-depletion benchmark cases were run with SAS2H and three fuel depletion cases were also run with the module.

The Shielding Analysis Sequence No. 2 (SAS2) control module was originally developed for the SCALE code system to provide a sequence that generated radiation source terms for spent fuel and subsequently utilized these sources within a onedimensional (1-D) shielding analysis of a shipping cask. The principal use of SAS2 over its history has been fuel depletion analysis to obtain radiation sources, decay heat, and spent fuel isotopics. The original SAS2 sequence was considerably enhanced as SAS2H for SCALE-4.

Six different codes plus several routines in the SCALE subroutine library are utilized by the SAS2H control module. The basic functions of the six functional modules are described below. The full details and description of the code system are presented in the SCALE manual (Reference 2). BONAMI applies the Bondarenko method of resonance self-shielding for nuclides that have Bondarenko data included with their cross sections. BONAMI and the Bondarenko methods and applicability are discussed in Reference 2. NITAWL-II performs the Nordheim resonance self-shielding corrections for nuclides that have resonance parameters included with their cross sections. NITAWL-II and the Nordheim Integral Treatment (NIT) are also discussed in Reference 2. XSDRNPM performs a 1-D discrete-ordinates transport calculation based on various specified geometries requested in the data supplied by SAS2H. The code, as applied by SAS2H, has three particular functions: to produce cell-weighted cross sections for fuel depletion calculations; to determine cell-weighted cross sections for spent fuel assemblies in a specified shipping cask; and to compute the angular flux data for the specified shipping cask, which are then applied by XSDOSE in computing dose rates.

The neutron transport analysis for each time-dependent fuel composition is basically a two-part procedure in which two separate lattice-cell calculations are performed, determining the neutron spectrum and, subsequently, the nuclide cross sections. At specified times during the burnup, the cross sections are updated using resonance processing codes and 1-D transport analyses. These updated cross sections are used in 
the depletion computation that produces the time-dependent fuel composition to be used for the next cross-section update. This sequence is repeated for the entire simulated operating history of the reactor.

For each time-dependent fuel composition, SAS2H performs 1-D neutron transport analyses (via XSDRNPM) using a two-part procedure with two separate lattice-cell models. The first model is a unit fuel-pin cell from which cell-weighted cross sections are obtained. The second model represents a larger unit cell (e.g., an assembly) within an infinite lattice. The fuel neutron flux spectrum obtained from the second (large) unit-cell model is used to determine the appropriate nuclide cross sections for the specified burnup-dependent fuel composition. The cross sections derived from a transport analysis at each time step are used in a point-depletion computation (via ORIGEN-S) that produces the burnup-dependent fuel composition to be used in the next spectrum calculation. In the study reported in this document, SAS2H was only applied to the pincell model for the VVER-1000 benchmark cases, concentrating on k-value determinations for most of the cases and also modeling fuel depletion isotopics for several burnup simulation cases.

The SAS2H sequence uses the ORIGEN-S code to model fuel depletion. The 1-D XSDRNPM code is used with SAS2H to model the neutronics and physics of the cases. XSDRNPM and the automatic quadrature generator, the unit-cell mesh generator, and convergence criteria applied by the code are discussed in Reference 2 . ORIGEN-S performs both nuclide generation and depletion calculations for the specified reactor fuel history. The code computes the neutron and gamma sources generated by the fuel. COUPLE updates the cross-section constants included on an ORIGEN-S nuclear data library with data from the cell-weighted cross-section library produced by XSDRNPM. The weighting spectrum computed by XSDRNPM is applied to update all nuclides in the ORIGEN-S library that were not specified in the XSDRNPM analysis.

The 1-D basis of XSDRNPM requires the use of the Wigner-Seitz equivalent cell in the representation of the actual hexagonal pin-cell geometry that is shown in Figure 3.1. The Wigner-Seitz pin-cell model represents the moderator as an annular region that conserves the appropriate ratio of moderator to fuel region. The moderation in the actual hexagonal pin-cell is greater than in the cylindrical Wigner-Seitz representation. Uranium is relatively insensitive to the small spectral effects so the Wigner-Seitz cylindrical approximation should not have a great effect. In MOX fuel cases, the plutonium in the fuel is more sensitive to spectral changes because of the $\sim 0.3 \mathrm{eV}$ resonances in ${ }^{239} \mathrm{Pu}$ and ${ }^{241} \mathrm{Pu}$, and the $1.1 \mathrm{eV}$ resonance in ${ }^{240} \mathrm{Pu}$.

Depletion calculations were only performed for benchmark fuel variants V1, V2, and V10 for state S1. The input files (see the Appendices) were designed such that output is provided at burnup steps of $2 \mathrm{MWd} / \mathrm{kgHE}$ for each case. The depletion cases were normalized to exactly $1 \mathrm{~kg}$ of heavy elements (initially) and the proper specific power density (from Table 2.3) was used.

In performing the depletion calculations with SCALE-4.3/SAS2H, it was discovered that in order to model the burnup history correctly, one has to include in the initial fuel compositions, in the input file, trace amounts of any potentially important nuclides. These long lists of nuclides can be seen in the fuel depletion cases in Appendices A to C. Originally, the author of this document tried to complete these depletion cases allowing 
SAS2H to use its internal default set of nuclides to model the burnup history: this was not sufficient, and led to large discrepancies between the earlier SAS2H depletion results and the results of the other codes.

The 238GROUPNDF5 nuclear data library was used for all the reported SAS2H benchmark simulation cases. The nuclide ${ }^{239} \mathrm{~Np}$ had to be left out of the specified fuel composition for fuel material FU3 and FU4 because it was not directly available with the 238GROUPNDF5 nuclear data library. This did not, however, have any significant impact on the calculational results.

For the SAS2H pin-cell benchmark cases that modeled boron in the moderator, it was discovered that one had to run a short burnup step to override the code's attempt to set the initial boron level to 1.45 times the input value for the initial calculations. The input case files in the Appendices have an initial $10^{-5}$ day burnup step to reset the boron levels to their appropriate concentrations.

\subsection{DESCRIPTION OF MODELING CODES USED IN OTHER STUDIES}

This subsection presents a description and some of the modeling details of the other codes used in various solutions of the VVER-1000 neutronics benchmarks.

\subsubsection{HELIOS}

HELIOS $^{5,6}$ is a two-dimensional neutron and gamma transport code lattice/fuel assembly analysis code developed by Studsvik Scandpower Inc. The neutron and gamma transport calculations in the code are based on current coupling of space elements. The situation within the spatial elements is modeled by collision probabilities. This is the CCCP (current-coupling collision-probability) method. The resonance treatment is based on the subgroup method. More specific details of the HELIOS code system are discussed in References 4 and 5.

The HELIOS code system comprises the AURORA input processor, the HELIOS calculational module, and the ZENITH output processor. The communication between the three codes is through a data base that is accessed and maintained by a subroutine package HERMES. Associated with the HELIOS code system is the ORION geometry viewer.

During HELIOS calculations, neutron fluxes and currents, and nuclide number densities are determined. Resonance-shielded microscopic cross sections are calculated. The fluxes and currents are calculated by the CCCP method for particle transport. Firstflight probabilities are evaluated. The criticality spectrum is evaluated by the $B_{1}$ method to rebalance the spectrum that was calculated in the CCCP stage. Bumup chains are then solved to obtain updated nuclide number densities.

The HELIOS nuclear data libraries are based on ENDF/B-VI release 2, with ${ }^{235} \mathrm{U}$ data from release 3. The ${ }^{238} \mathrm{U}$ resonance integral in the production libraries was reduced by $3.4 \%$ to improve agreement with critical experiments. The HELIOS libraries contain data for 271 nuclides, including 32 actinides and 115 fission product nuclides. The HELIOS-1.4 nuclear data libraries are available in 34,89 , and 190 neutron energy 
groups. The HELIOS-1.4 benchmark results ${ }^{3}$ were all determined using the 190-group nuclear data library.

\subsubsection{MCU-RFFI/A}

MCU-RFFI/A is a general-purpose continuous-energy Monte Carlo code for solving the neutron transport problems in the energy range from $10^{-5} \mathrm{eV}$ up to $20 \mathrm{MeV}$. A description of the code is presented in Reference 1. The code is a part of the MCU project. This project includes development of the nuclear data libraries and the codes for processing library data, designing and updating the Monte Carlo code package, and supporting and updating the CLAD library, containing MCU input lists and the results of MCU calculations for a variety of problems ( $\sim 300$ assemblies). The MCU-RFFI/A executable is assembled from modules in the MCU code package. The modular code architecture permits the solution of transport problems using a set of various algorithms and exchangeable program modules while also using different data libraries. The code is used with pointwise and step-function representations of cross sections. To describe the unresolved resonance cross sections a subgroup method is used, similar to the probability table method. A detailed cross section representation is used in the resolved resonance region: for the important nuclides, a near-infinite number of energy points is used to describe the resonance curve. The cross sections are calculated at every energy point on the basis of the resonance parameter library, and temperature effects can be estimated. For the thermal energy range, the Monte Carlo algorithm uses the $S(\alpha, \beta)$ scattering laws and coherent elastic scattering or free gas models. In the solutions, both the prompt neutron and the delay neutron spectra can be distinctly included.

The accuracy of the nuclear data has a major influence on the results of a Monte Carlo code. MCU-RFFI/A code verification and validation was based on the DLC/MCUDAT-1.0 composite library, which includes the ACE library prepared by NJOY from ENDF/B-VI data, the ABBN 26-group library, the LIPAR library of nuclear resonance parameters for the resolved resonance region, the VESTA library of continuous-energy thermal neutron cross sections, and the TEPCON thermal neutron data multigroup library (which is an alternative to VESTA). MCU-RFFI/A with the DLC/MCUDAT-1.0 library were certified by GAN in 1996 for use as a tool to perform criticality calculations for most neutron multiplication systems including those with plutonium or MOX fuels.

The scattering laws for the VESTA and TEPCON libraries are calculated using ENDF data. The ACE library is used only for energies above $100 \mathrm{keV}$. The ABBN library is used to describe smooth cross sections (with step functions) for energies above the resolved resonance range. Inelastic scattering is modeled using probability density step functions. LIPAR data are directly used in the code for calculating the continuous energy cross sections taking into account Doppler broadening. Both continuous energy (VESTA) and the multigroup approximation (TEPCON) can be used in the thermalization region. For most moderators, the scattering cross sections are calculated using Gauss's incoherent approximation. If necessary, the elastic coherent cross sections are also used. DLC/MCUDAT-1.0 also includes the DOSIM (prepared using NJOY) library which includes data for dosimetry reaction rate calculations. 
MCU-RFFI/A allows the user to model an arbitrary, 3-D system described by combinatorial geometry. Geometry zones are represented by combinations of 13 different geometric bodies. Boundary conditions include vacuum, white, spectral reflection, translational symmetry, and symmetry planes. Criticality cases may be solved in Benoist's method with neutron leakage represented by buckling. Doubly heterogeneous systems (fuel elements with detailed microcells) can be modeled.

\subsubsection{TVS-M}

TVS-M is a spectral code used for calculations of VVER neutronics constants for cells, supercells, and fuel assemblies. A description of the TVS-M code is given in References 1 and 6. TVS-M is part of the code package for VVER calculations. The nuclear data library used by TVS-M is essentially the same as the nuclear data used with MCU-RFFI/A. For the fast energy region ( $>4.65 \mathrm{keV}$ ) the ABBN multigroup cross section library is used. This fast energy range includes 12 groups of the library. For the resonance energy range $\left(4.65 \mathrm{keV}>E_{n}>0.625 \mathrm{eV}\right)$ the $13^{\text {th }}$ to the $24^{\text {th }} A B B N$ groups are used, with a modification to the $24^{\text {th }}$ group because of mismatched lower energy boundaries. In the resonance range, TVS-M uses both group and subgroup constants. The resonance parameters from the LIPAR-3 library are applied for resonance nuclides. For these nuclides, the cross section calculation is based on the Breit-Wigner multilevel model; for the fissile nuclides, the Adler-Adler model is considered.

The thermal energy range $(<0.625 \mathrm{eV}$ ) is subdivided into 24 groups. A set of scattering matrices for various temperatures (calculated with the Koppel-Young model) is applied to the hydrogen in the water molecules. The group cross sections of nuclides and the scattering matrices have been obtained from the same nuclear data (TEPCON library) and the same algorithms as for the MCU-RFFU/A code. For depletion calculations, 96 fission products are considered. TVS-M uses a library of fission product yields based on ENDF/B-VI data and group cross sections from the MCU data library.

The TVS-M calculational methodology follows stages. First, a detailed calculation of all cell types in a fuel assembly (i.e. fuel cell, absorber cell, etc.) is performed. Corresponding sets of few-group constants are determined. Next, these constants are used in a nodal diffusion calculation of the whole assembly. Neutron spatial distributions (in the specified group structure) are calculated with the passing-through probability methods, which is similar to the first collision probability method. Neutron reflection at the cell boundary takes into account the actual hexagonal geometry of the boundary.

In the fast energy range, detailed calculations are performed with the use of group and subgroup microscopic cross sections from the $\mathrm{ABBN}$ library. The energy losses of neutrons through elastic and inelastic slowing down are described continuously, taking into account scattering anisotropy in a system of inertial centers. In the resonance energy region, the slowing down of neutrons is calculated in the same manner as for fast neutrons. Resonance nuclide cross sections are calculated for each energy value with the CROSS code using resonance parameters files for each nuclide. Interference is taken into account between potential and resonance scattering, temperature dependence of cross sections, and p-wave contributions to the scattering cross sections. The effect of mutual overlap of different resonance nuclides is also taken into account. For the thermal energy range, the group thermalization equation is solved by the passing-through probability 
method. Sources are shaped when the upper energy groups are calculated. The Nelkine asymptotic limit of scattering is applied for hydrogen.

A nodal diffusion approach (with asymptotic and transient trial functions) for both neutron flux and neutron current is applied for a pin-by-pin calculation of the fuel assembly being modeled. The transient situation corresponds to finding the neutron distribution in the cell placed at the center of a supercell when a source in it is equal to zero. In such a supercell, the fuel cell is surrounding by water and a cell of the other type (l.e., homogenized fuel cells). A correction for mesh width in the balance equation compensates for the difference between average flux levels and the flux at the cell boundary. A similar correction is applied to the neutron current flowing through the cell.

Fuel depletion is modeled with TVS-M by burnup equations that are solved for every fuel pin, which can be subdivided into concentric rings (i.e., separate burnup zones). In addition to the fission product calculations, concentrations of 20 nuclides of Th to $\mathrm{Cm}$ are explicitly calculated with burnup. Equilibrium concentrations of ${ }^{135} \mathrm{Xe}$ and ${ }^{149} \mathrm{Sm}$ are also calculated.

\subsubsection{WIMS-ABBN}

The WIMS-ABBN code is an updated version of the WIMS-D4 code. A description of WIMS-ABBN is presented in Reference 1. The code has an updated nuclear data library and includes minor actinide chains in the calculations. Most structural materials, all neutron absorbers, and all actinides were updated in the WIMS-D4 library. Data were added for $\mathrm{Sn}, \mathrm{Mo}, \mathrm{Ta}$, and $\mathrm{W}$, and for the minor actinides ${ }^{237} \mathrm{~Np},{ }^{238} \mathrm{Pu},{ }^{241} \mathrm{Am},{ }^{242} \mathrm{Am}$, ${ }^{242 \mathrm{~m}} \mathrm{Am},{ }^{243} \mathrm{Am},{ }^{242} \mathrm{Cm},{ }^{243} \mathrm{Cm},{ }^{244} \mathrm{Cm}$, and ${ }^{245} \mathrm{Cm}$. Data for fission products were also updated. FP yields from ${ }^{235} \mathrm{U}$ and ${ }^{239} \mathrm{Pu}$ were updated, and yield data were added for the other fissile nuclides. Data for the new WIMS-D4 library were calculated on the basis of the FOND-2 evaluated nuclear data library. The ENDF/B-VI and JEF-2 nuclear data libraries were also used.

Resonance self-shielding data were calculated with the GRUCON code for cases when the narrow resonance approximation is sufficient. NJOY was used for all fuel nuclides for calculation of resonance self-shielding data, with considerations for fluctuations of collision probability density. Thermalization matrices for moderators were calculated with NJOY from ENDF/B-VI data. Scattering anisotropy is modeled in the P1 approximation. NJOY was also used to calculate average group cross sections and matrices for intergroup transitions. ACTWIMS, an additional neutron reaction cross section library, was compiled. It includes data for more nuclides and reaction types than the main WIMS-D4 library. Energy boundaries in the libraries are consistent, so ACTWIMS data could be collapsed using the neutron spectra from WIMS. A set of 48 nuclides (16 actinides, 31 FPs, and oxygen) is used.

Improvements to WIMS-D4 include the extension of resonance self-shielding of neutron cross sections to the thermal energy range. This will benefit the accurate treatment of neutron capture in ${ }^{242} \mathrm{Pu}$, which has a resonance energy level at a very low energy. Another improvement to the code is the addition of the module AVERAGE to collapse the ACTWIMS cross sections in the cell-averaged neutron spectra calculated by WIMS. The number of nuclear reactions considered during actinide generation was 
extended, but the structure of the WIMS-D4 library does not allow for the inclusion of some important reactions. The production of ${ }^{242} \mathrm{Am}$ and ${ }^{242 \mathrm{~m}} \mathrm{Am}$ through neutron capture by ${ }^{241} \mathrm{Am}$ cannot be considered as WIMS-D4 cannot treat branching in the capture process. Production of ${ }^{242} \mathrm{Cm}$ and ${ }^{243} \mathrm{Cm}$ cannot be modeled correctly. The $(\mathrm{n}, 2 \mathrm{n})$ reaction cannot be considered if the $(n, \gamma)$ reaction is included. To correct this shortcoming, the code CREDE was developed.

CREDE works in conjunction with WIMS-D4 and AVERAGE, and is used for calculating heavy metal $(\mathrm{HM})$ concentrations during burnup simulations and during long decay periods. In CREDE depletion calculations, one-group microscopic cross sections are taken from the WIMS library or, if not present, the ACTWIMS library. The neutron flux required for the CREDE calculations either comes from WIMS or is computed in CREDE itself from the specific power level. At each burnup step, the neutron flux and microscopic cross sections are updated. 


\section{RESULTS AND DISCUSSION}

The SCALE-4.3 SAS2H results from an Oak Ridge National Laboratory analysis of the weapons-grade MOX VVER-1000 pin-cell neutronics benchmark study are presented in this section. The SAS2H results are compared to the results from the HELIOS-1.4 benchmark study also performed at ORNL and documented in Reference 3. The benchmark results from three Russian codes are also compared. The Russian results are documented in Reference 1 and include calculations using MCU-RFFI/A, TVS-M, and WIMS-ABBN.

Zero-burnup results are shown in Section 4.1 for cases with benchmark variants V1V4 and V7-V10 for states S1 to S6. The calculations were performed using the official benchmark specifications including the large given value for the buckling, $B^{2}=0.003 \mathrm{~cm}^{-2}$.

In addition to the zero-burnup cases, three fuel depletion cases were completed using SAS2H. The fuel depletion cases were for variants V1 (LEU), V2 (weapons-grade Pu $\mathrm{MOX}$ ), and V10 (reactor-grade Pu MOX) all with State S1, for a burnup history from 0 to $60 \mathrm{MWd} / \mathrm{kgHE}$. These results are presented in Section 4.2.

\subsection{BENCHMARK RESULTS FOR CASES WITHOUT FUEL DEPLETION}

The $\mathrm{k}_{\mathrm{eff}}, \mathrm{k}_{\mathbf{0}}$, and $\mathrm{k}_{\mathrm{inf}}$ results of the SAS2H zero-burnup benchmark cases are presented in Table 4.1. These data represent the completion of 80 individual SAS2H runs. Most of these calculations were also repeated with the SCALE-4.3/CSAS module, to confirm the results; the results were identical.

In Table 4.2, the SAS2H k-values are tabulated along with the results from the earlier HELIOS study and several sets of Russian code results. Some of the calculations performed in Russia used different definitions than the standard state and composition definitions, particularly with respect to the amounts of ${ }^{135} \mathrm{Xe}$ and ${ }^{149} \mathrm{Sm}$ modeled. For the Russian code TVS-M, several distinct sets of results (indicated by different colors and superscripts) were presented in Reference 1 with various different modeling nuances.

For fuel variant V9, the $k_{o}$ values for $S 1$ and $S 6$ from Reference 1 (Table 4.139) were clearly typographical errors in Reference 1 . These data are still included in Table 4.2 for completeness, the problem in the $\mathrm{k}_{\mathrm{o}}$ values are flagged by a footnote (the corresponding $k_{\text {eff }}$ values are not consistent with the $k_{o}$ values). Generally, once the differences in the simulated state definitions are taken into account, there is good agreement between the results of SAS2H, MCU-RFFI/A, HELIOS, and TVS-M.

In terms of reactivity $\% \Delta \mathrm{k} / \mathrm{k}^{2}=100\left[\left(\mathrm{k}_{\mathrm{SASPH}}-\mathrm{k}_{\mathrm{HELLOS}}\right) / \mathrm{k}_{\mathrm{SAS22}} \mathrm{k}_{\mathrm{HELLOS}}\right)=100\left(1 / \mathrm{k}_{\text {HELOSS }}-1 / \mathrm{k}_{\text {SAS2H }}\right)$, the differences in k-values between SAS2H and HELIOS show trends. Table 4.3 shows the reactivity differences between the SAS2H and the HELIOS k-value determinations. Values for $k_{\text {inf }}$ are systematically slightly higher in HELIOS than in SAS2H. For the 40 cases shown in Table 4.2, the HELIOS $\mathrm{k}_{\text {inf }}$ is higher than the SAS2H $\mathrm{k}_{\text {inf }}$ by an average of $1.07 \pm 0.06 \% \Delta \mathrm{k} / \mathrm{k}^{2}$. Values for $\mathrm{k}_{\mathrm{eff}}$, on the other hand, are generally slightly higher for SAS2H than for HELIOS, by an average of $1.03 \pm 0.10 \% \Delta \mathrm{k} / \mathrm{k}^{2}$. The agreement between SAS2H and HELIOS results for all the benchmark variants in State S6 is the best: $0.46 \pm 0.13 \% \Delta \mathrm{k} / \mathrm{k}^{2}$ for differences in $\mathrm{k}_{\text {inf }}$ and $-0.64 \pm 0.11 \% \Delta \mathrm{k} / \mathrm{k}^{2}$ for $\mathrm{k}_{\text {inf }}$ and $0.46 \pm 0.13$ $\% \Delta \mathrm{k} / \mathrm{k}^{2}$ for $\mathrm{k}_{\text {eff. }}$ The difference between SAS2H and HELIOS $\mathrm{k}$-values for the other state 
sets are similar: -1.07 to $-1.23 \% \Delta \mathrm{k} / \mathrm{k}^{2}$ for $\mathrm{k}_{\text {inf }}$, and 1.10 to $1.27 \% \Delta \mathrm{k} / \mathrm{k}^{2}$ for $\mathrm{k}_{\text {eff. For }}$ subsets of results by benchmark variant (for all states) the best average agreement $\mathrm{S}-\mathrm{H}$ for $\mathrm{k}_{\text {eff }}$ is V9 with $-0.14 \pm 0.06 \% \Delta \mathrm{k} / \mathrm{k}^{2}$, the corresponding kinf difference is the largest, $-1.69 \pm 0.13 \% \Delta \mathrm{k} / \mathrm{k}^{2}$. The $\mathrm{k}_{\mathrm{eff}}$ disagreement for $\mathrm{V} 2$ is the worst, at $1.44 \pm 0.16 \% \Delta \mathrm{k} / \mathrm{k}^{2}$, with a corresponding $\mathrm{k}_{\text {inf }}$ difference of $-0.76 \pm 0.11 \% \Delta \mathrm{k} / \mathrm{k}^{2}$; this is also the average $\mathrm{k}_{\text {inf }}$ difference for benchmark variant V7 cases.

Reactivity effect values are of greater importance and interest than the absolute kvalues themselves. From the k-values presented in Table 4.1 and 4.2, sets of reactivity differences were calculated from the results from each computer code for six pertinent quantities and reactor state changes. These reactivities are listed in Table 4.4 in terms of $\% \Delta \mathrm{k} / \mathrm{k}^{2}$; that is, $\Delta \rho=100\left[\left(\mathrm{k}_{1}-\mathrm{k}_{2}\right) / \mathrm{k}_{1} \mathrm{k}_{2}\right]=100\left(1 / \mathrm{k}_{1}-1 / \mathrm{k}_{2}\right)$. The reactivity differences based on $k_{\text {eff }}$ are significantly different from those based on $k_{0}$ or $k_{\text {inf. }}$. This is most likely because of the neutron leakage behavior related to the large buckling value $B^{2}=0.003 \mathrm{~cm}^{-2}$ that is specified in Reference 1.

The reactivity differences for cold-to-hot coolant include the major effect of coolant density decrease from the expansion at hot temperatures, and the associated effective reduction in the coolant boron concentration. In Table 4.4, it is seen that these reactivity values have the largest differences between the results from $k_{\text {eff }}$ and the results from $k_{o}$ and $k_{\text {inf. }}$ These $k_{\text {eff }} v s k_{o}$ and $k_{\text {inf }}$ differences are carried through to the "cold-to-hot reactor" reactivity effects seen in Table 4.4.

The boron worth reactivity effect determinations (based on states S1 and S3) from MCU and TVS-M as presented in Table 4.4 have actually been corrected for various concentration levels of ${ }^{149} \mathrm{Sm}$ and ${ }^{135} \mathrm{Xe}$ in the Russian benchmark $\dot{S} 1$ and S3 calculations. These modeling differences are discussed in the footnotes to Table 4.2. The corrected values presented in Table 4.4 are approximate since the reactivity worth of boron will be somewhat different when calculated in the presence of different levels of ${ }^{135} \mathrm{Xe}$ and ${ }^{149} \mathrm{Sm}$. Once the variable reactivity effects for ${ }^{149} \mathrm{Sm}$ and ${ }^{135} \mathrm{Xe}$ are subtracted, the boron worth reactivity effect values from the Russian codes and the HELIOS and SAS2H calculations come into good general agreement. The reactivity worths for boron, and for ${ }^{135} \mathrm{Xe}$ and ${ }^{149} \mathrm{Sm}$, are seen to be larger for LEU fuel (V1) than for the MOX cases (V2 and V10), as expected from neutron spectral considerations. The reactivity worth calculations for ${ }^{135} \mathrm{Xe}$ and ${ }^{149} \mathrm{Sm}$ (based on the state $\mathrm{S} 1$ and S4 k-values shown in Table 4.2) are in good general agreement for all the codes.

The reactivity effects from fuel temperature changes (Doppler broadening) and coolant expansion and coolant temperature increase are consistently slightly larger for SAS2H calculations than for the other codes, for all the benchmark cases. For the coldto-hot reactivity effects: generally, HELIOS, MCU, and TVS-M results agree to within about 1 to $5 \%$. SAS2H results agree to within about 5 to $10 \%$. 
Table 4.1. SCALE-4.3/SAS2II zero-burnup benchmark results: V1-V10, states S1-S6.

\begin{tabular}{|c|c|c|c|c|c|c|c|c|c|c|c|c|c|c|c|}
\hline \multirow{2}{*}{$\begin{array}{c}\text { State } \rightarrow \\
\text { Benchmark } \\
\text { Variant } \downarrow\end{array}$} & \multicolumn{3}{|c|}{ S1 } & \multicolumn{3}{|c|}{ S3 } & \multicolumn{3}{|c|}{ S4 } & \multicolumn{3}{|c|}{ S5 } & \multicolumn{3}{|c|}{ S6 } \\
\hline & $\mathbf{k}_{\text {eff }}$ & $\mathbf{k}_{\mathbf{0}}$ & $\mathbf{k}_{\text {inf }}$ & $\mathbf{k}_{\text {eff }}$ & $\mathbf{k}_{\mathbf{0}}$ & $\mathbf{k}_{\text {inf }}$ & $k_{\text {eff }}$ & $\mathbf{k}_{\mathbf{0}}$ & $\mathbf{k}_{\text {inf }}$ & $\mathbf{k}_{\text {eff }}$ & $\mathbf{k}_{\mathbf{0}}$ & $\mathbf{k}_{\mathrm{inf}}$ & $k_{\text {eff }}$ & $\mathbf{k}_{\mathbf{o}}$ & $\mathbf{k}_{\text {inf }}$ \\
\hline V1 & 1.0800 & 1.2539 & 1.2589 & 1.1264 & 1.3084 & 1.3140 & 1.1199 & 1.3007 & 1.3065 & 1.1350 & 1.3189 & 1.3245 & 1.2286 & 1.3636 & 1.3669 \\
\hline $\mathbf{V} 2$ & 1.0396 & 1.2028 & 1.2054 & 1.0638 & 1.2311 & 1.2339 & 1.0562 & 1.2222 & 1.2250 & 1.0745 & 1.2439 & 1.2466 & 1.1948 & 1.3227 & 1.3248 \\
\hline V3 & 0.9270 & 1.0780 & 1.0818 & 0.9645 & 1.1220 & 1.1264 & 0.9602 & 1.1170 & 1.1215 & 0.9765 & 1.1365 & 1.1410 & 1.0680 & 1.1873 & 1.1902 \\
\hline V4 & 0.8718 & 1.0122 & 1.0156 & 0.9055 & 1.0516 & 1.0556 & 0.9013 & 1.0467 & 1.0508 & 0.9163 & 1.0646 & 1.0686 & 1.0060 & 1.1171 & 1.1197 \\
\hline V7 & 1.1225 & 1.3002 & 1.3036 & 1.1500 & 1.3324 & 1.3361 & 1.1414 & 1.3222 & 1.3259 & 1.1578 & 1.3419 & 1.3445 & 1.2714 & 1.4088 & 1.4105 \\
\hline V8 & 0.9355 & 1.0850 & 1.0896 & 0.9807 & 1.1380 & 1.1434 & 0.9769 & 1.1335 & 1.1390 & 0.9939 & 1.1540 & 1.1593 & 1.0893 & 1.2082 & 1.2115 \\
\hline V9 & 1.3211 & 1.5239 & 1.5279 & 1.3513 & 1.5590 & 1.5633 & 1.3403 & 1.5460 & 1.5503 & 1.3596 & 1.5690 & 1.5732 & 1.4638 & 1.6169 & 1.6189 \\
\hline V10 & 0.9651 & 1.0957 & 1.0950 & 0.9760 & 1.1082 & 1.1076 & 0.9701 & 1.1014 & 1.1007 & 0.9861 & 1.1200 & 1.1194 & 1.0930 & 1.1935 & 1.1937 \\
\hline
\end{tabular}




\begin{tabular}{|c|c|c|c|c|c|c|c|c|c|}
\hline$\stackrel{\Xi}{\sharp}$ & 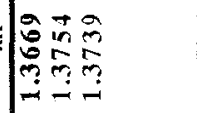 & 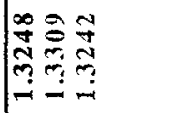 & 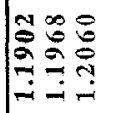 & 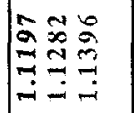 & 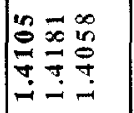 & 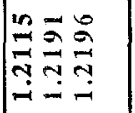 & $\mid \begin{array}{ccc}\infty & \infty & 0 \\
\infty & 0 & 0 \\
0 & 1 & 0 \\
-1 & 0 & 0 \\
-1 & 0 & 0\end{array}$ & 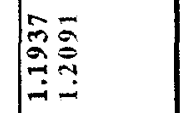 & \\
\hline$\dot{0}:=0$ & 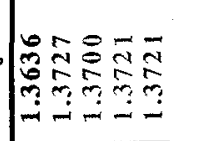 & 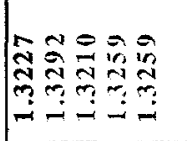 & 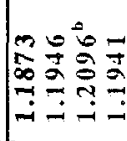 & & 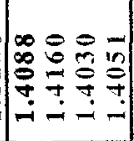 & 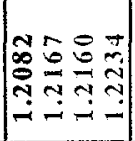 & 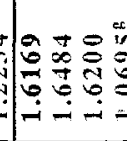 & 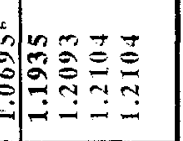 & \\
\hline$\stackrel{5}{ \pm}$ & 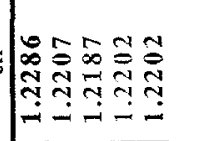 & 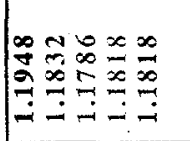 & 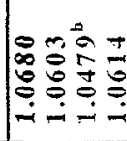 & & 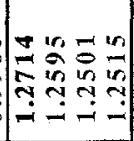 & 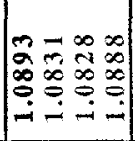 & 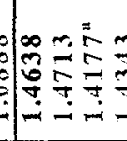 & 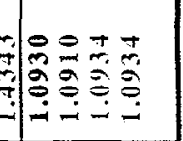 & \\
\hline 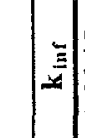 & $\mid$ & 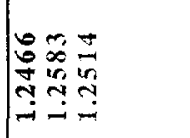 & 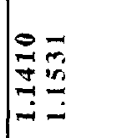 & 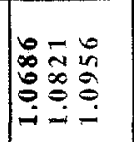 & 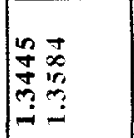 & 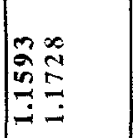 & 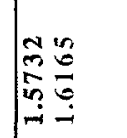 & 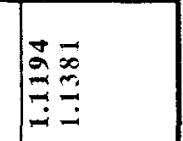 & $\ddot{t} \ddot{b}$ \\
\hline$\infty$ & $\mid \begin{array}{ll}\infty \\
\infty\end{array}$ & 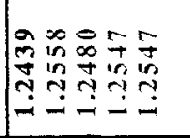 & 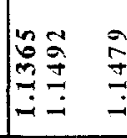 & 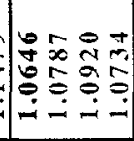 & 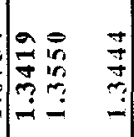 & 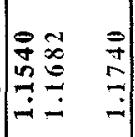 & $\mid \begin{array}{ll}0 \\
0 \\
0\end{array}$ & 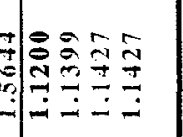 & 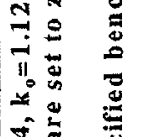 \\
\hline 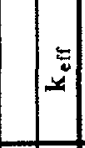 & 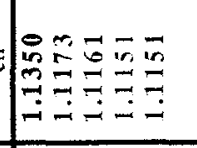 & 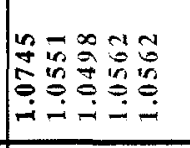 & 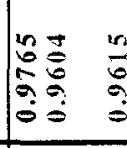 & 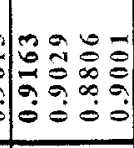 & 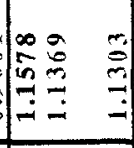 & $\begin{array}{l}2 \\
0= \\
20 \\
0= \\
0\end{array}$ & : & 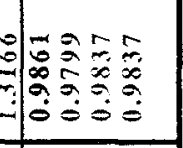 & 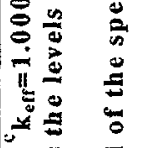 \\
\hline$\cong$ & 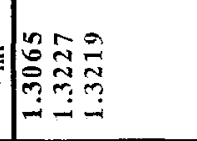 & 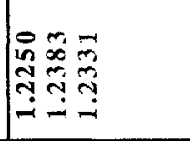 & 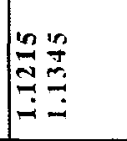 & 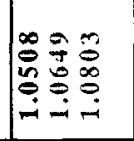 & $\underset{1}{3}=$ & 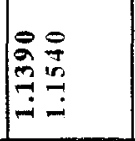 & 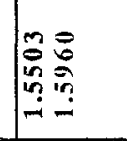 & 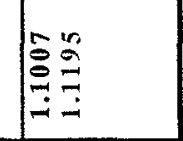 & 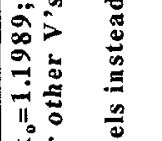 \\
\hline 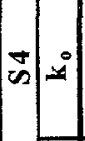 & $\mid \begin{array}{ll}n \\
0\end{array}$ & 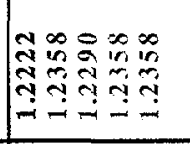 & $\underset{7}{0}$ & 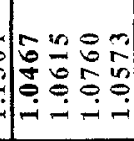 & 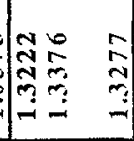 & $\overbrace{2}^{2}$ & : & 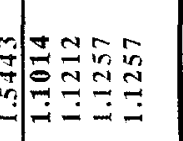 & $\begin{array}{ll} & 0 \\
0 & 0 \\
0 & 0 \\
0 & 0\end{array}$ \\
\hline$=$ & 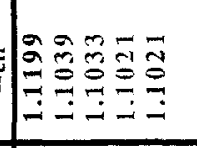 & 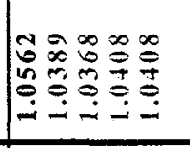 & 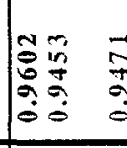 & 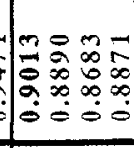 & $\mid$\begin{tabular}{ll}
2 \\
\hdashline
\end{tabular} & $\begin{array}{l}0 \\
0 \\
0 \\
0 \\
0 \\
0 \\
0 \\
0\end{array}$ & 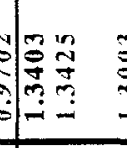 & 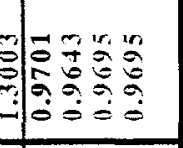 & 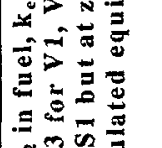 \\
\hline 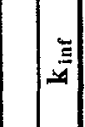 & $\mid$\begin{tabular}{ll}
0 \\
\hdashline
\end{tabular} & 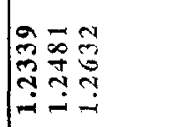 & 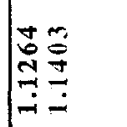 & 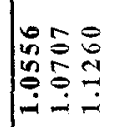 & 苛 & 要 & 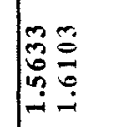 & 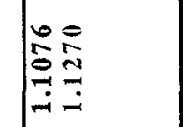 & 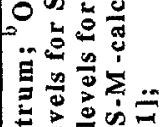 \\
\hline 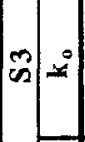 & 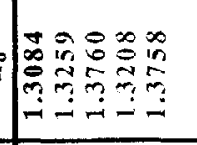 & 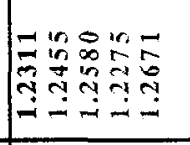 & 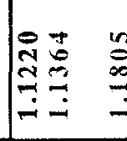 & 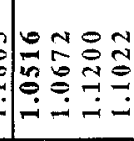 & $\mid \begin{array}{cc}0 \\
2\end{array}$ & 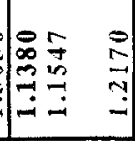 & ent & 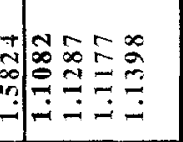 & 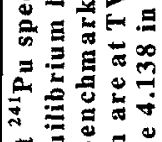 \\
\hline 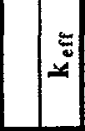 & 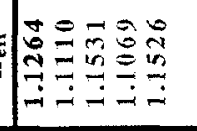 & 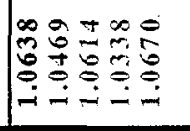 & 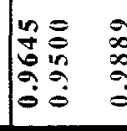 & 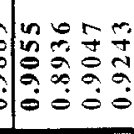 & 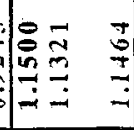 & 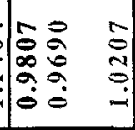 & $\hat{n}$ & 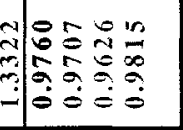 & 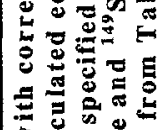 \\
\hline \multirow{5}{*}{$\vec{\infty}}$. & 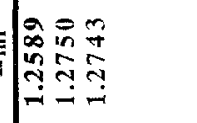 & 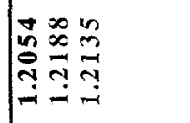 & 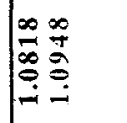 & 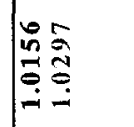 & $\mid \begin{array}{ll}0 & 0 \\
0 & \infty \\
0 & 0 \\
0 & 0\end{array}$ & 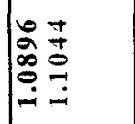 & 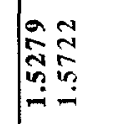 & 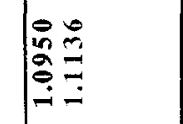 & 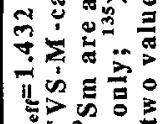 \\
\hline & 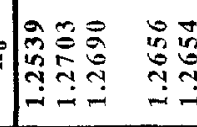 & 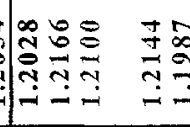 & 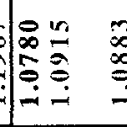 & $: \begin{array}{l}1 \\
0\end{array}$ & 资 & 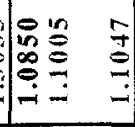 & 包 & $\begin{array}{c}0 \\
0 \\
0\end{array}$ & 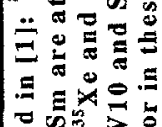 \\
\hline & 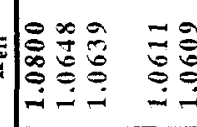 & 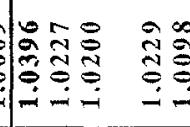 & 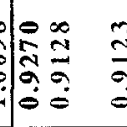 & 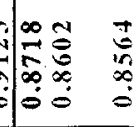 & 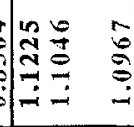 & 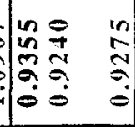 & 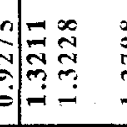 & 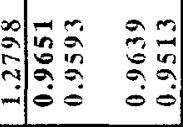 & 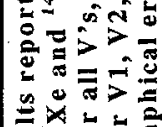 \\
\hline & 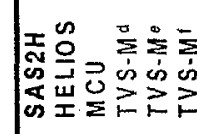 & 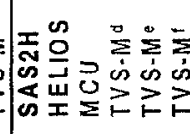 & 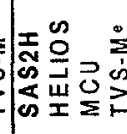 & 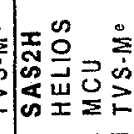 & 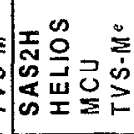 & 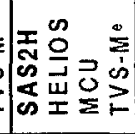 & 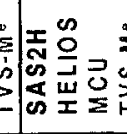 & 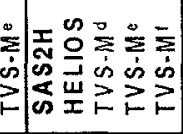 & $\Xi 3$ \\
\hline & $\mathbf{I} \boldsymbol{\Lambda}$ & $z_{A}$ & $\mathcal{E}_{\boldsymbol{\Lambda}}$ & $\nabla \Lambda$ & $L \Lambda$ & $8 \Lambda$ & $6 \Lambda$ & $0\llcorner\Lambda$ & \\
\hline
\end{tabular}


Table 4.3. Reactivity differences between SAS2H and HELIOS k-values results.

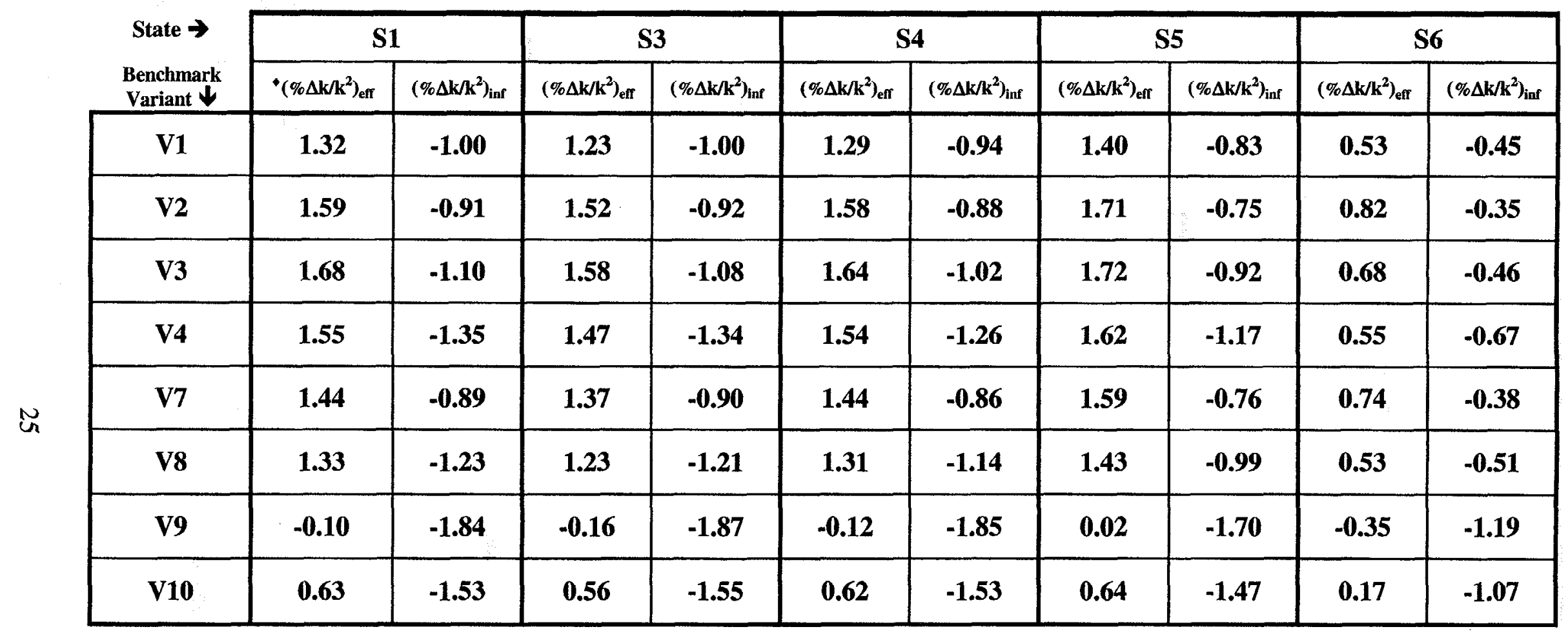

- $\Delta \mathrm{k}$ is the difference between the SAS2H and HELIOS results. The reactivity differences tabulated in all the columns are equal to $100\left(1 / \mathrm{k}_{u r}\right.$ inc $\left.-1 / \mathrm{k}_{\mathrm{c} \wedge \mathrm{cus}}\right)$ 
Table 4.4. Reactivity effects by fuel variant, state changes, and computer code.

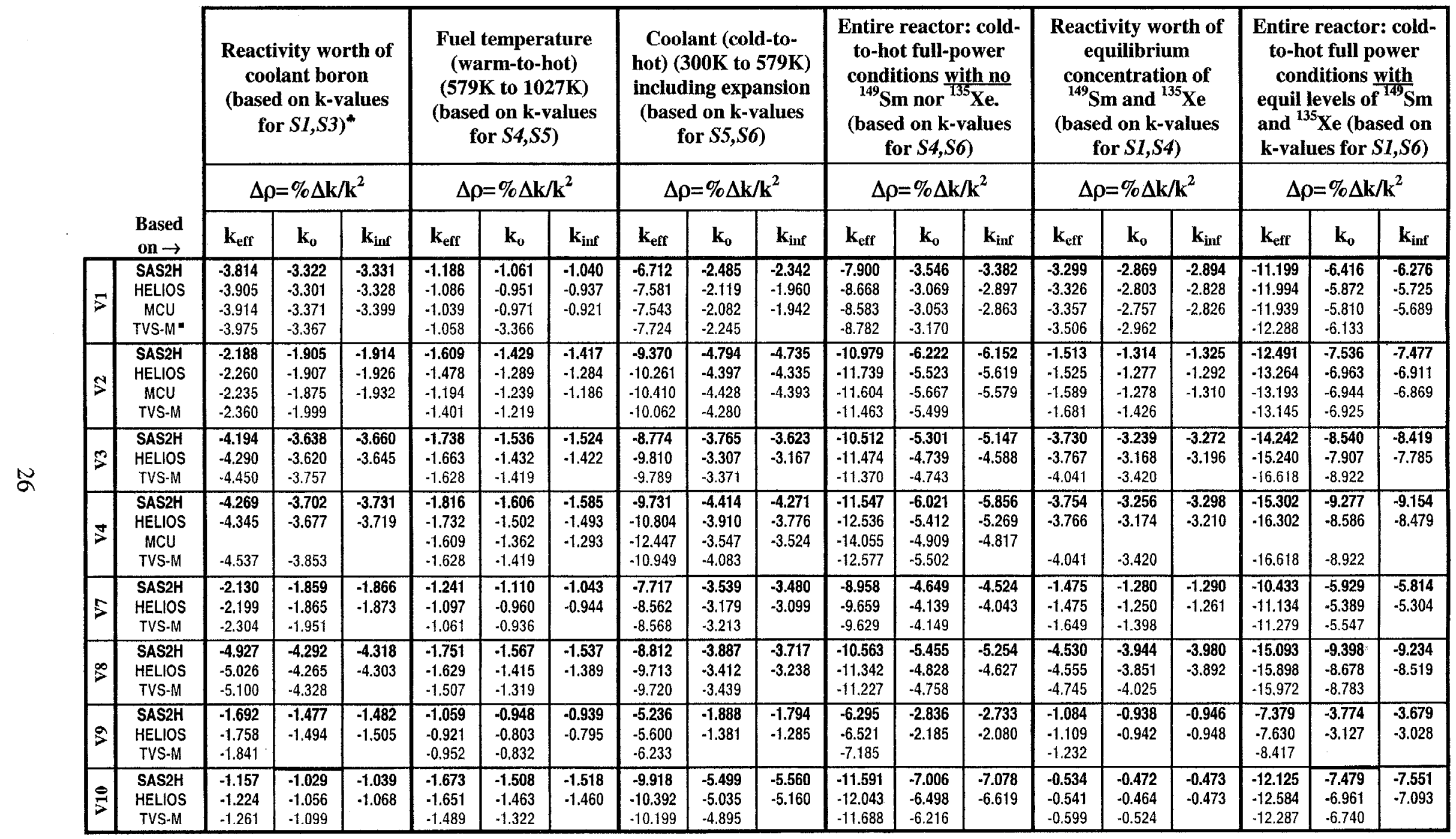

Note: MCU and TVS-M coolant boron $\Delta \rho$ values are corrected approximately for effects of various ${ }^{135}$ Xe and ${ }^{149}$ Sm levels discussed in notes to Table 4.2 , using appropriate Russian data.
- The TVS-M data shown in this table are all calculated from the Russian k-determinations from Table 4.138 of Reference 1 , which were presented in Table 4.2 of this report as TVS-M 


\subsection{BENCHMARK RESULTS FOR CASES WITH FUEL DEPLETION}

The results from three fuel depletion simulations performed with SAS2H as part of the benchmark study are presented below. The three fuel depletion cases are with fuel variants V1 (LEU UO $)_{2}$ ), V2 (WG MOX), and V10 (RG MOX), all at State S1 conditions and with the specific power densities shown in Table 2.3. The case burnup steps were chosen to provide results at every $2 \mathrm{MWd} / \mathrm{kgHE}$ burnup increment between 0 and $60 \mathrm{MWd} / \mathrm{kgHE}$. The case input files are included as Appendices A to C. The SAS2H results for the fuel depletion cases are also compared to results from the ORNL study with HELIOS and from two Russian studies with TVS-M and with WIMS-ABBN. In Table 4.5, the results are summarized in terms of the initial and discharge $k$-values. These comparisons are seen graphically in Figure 4.1.

Table 4.5. Comparison of $\mathrm{k}_{\text {eff }}$ and $\mathrm{k}_{\mathrm{o}}$ calculations in state $\mathrm{S} 1$ fuel depletion simulations.

\begin{tabular}{|c|c|c|c|c|c|}
\hline \multirow{2}{*}{ Fuel Variant } & \multirow{2}{*}{ Computer Code } & \multicolumn{2}{|c|}{ BOL Fuel (0 MWd/kgHE) } & \multicolumn{2}{l|}{ EOL Burnup (60 MWd/kgHE) } \\
\cline { 2 - 6 } & & $\mathbf{k}_{\mathbf{o}}$ & $\mathbf{k}_{\text {eff }}$ & $\mathbf{k}_{\mathbf{o}}$ & $\mathbf{k}_{\text {eff }}$ \\
\hline \multirow{3}{*}{ V1 } & SAS2H & 1.2539 & 1.0800 & 0.8581 & 0.7411 \\
\cline { 2 - 6 } & HELIOS & 1.2703 & 1.0648 & 0.8557 & 0.7161 \\
\cline { 2 - 6 } & TVS-M & 1.2654 & 1.0609 & 0.8542 & 0.7143 \\
\cline { 2 - 6 } & WIMS-ABBN & 1.2614 & 1.0572 & 0.8541 & 0.7179 \\
\hline \multirow{4}{*}{ V2 } & SAS2H & 1.2028 & 1.0396 & 0.8445 & 0.7315 \\
\cline { 2 - 6 } & HELIOS & 1.2166 & 1.0227 & 0.8451 & 0.7098 \\
\cline { 2 - 6 } & TVS-M & 1.1988 & 1.0098 & 0.8434 & 0.7076 \\
\cline { 2 - 6 } & WIMS-ABBN & 1.2004 & 1.0149 & 0.8401 & 0.7093 \\
\hline \multirow{3}{*}{ V10 } & SAS2H & 1.0957 & 0.9651 & 0.9172 & 0.8090 \\
\cline { 2 - 6 } & HELIOS & 1.1154 & 0.9593 & 0.9291 & 0.7982 \\
\cline { 2 - 6 } & TVS-M & 1.1045 & 0.9513 & 0.9170 & 0.7869 \\
\cline { 2 - 6 } & WIMS-ABBN & 1.1013 & 0.9517 & 0.9206 & 0.7952 \\
\hline
\end{tabular}

With the SCALE-4.3/SAS2H sequence, only one fuel region can be modeled in a fuel pincell simulation. In HELIOS for example, the fuel can be modeled as concentric regions, permitting the modeling of the important outer annulus of the fuel for MOX fuel burnup simulations. Some small offsets in $\mathrm{k}$ determinations result when only one fuel region is considered. To assess this, a test case with HELIOS-1.4 for variant benchmark V2, changing the fuel region representation to just one fuel region as in SAS2H, results in a $-0.08 \% \Delta \mathrm{k} / \mathrm{k}^{2}$ reactivity drop in $\mathrm{k}_{o}$ and a $-0.09 \% \Delta \mathrm{k} / \mathrm{k}^{2}$ reactivity drop in $\mathrm{k}_{\text {eff }}$ for $\mathrm{BOL}$, and a $-0.23 \% \Delta \mathrm{k} / \mathrm{k}^{2}$ drop in $\mathrm{k}_{\mathrm{o}}$ and $\mathrm{a}-0.27 \% \Delta \mathrm{k} / \mathrm{k}^{2}$ drop in $\mathrm{k}_{\text {eff }}$ at $60 \mathrm{MWd} / \mathrm{kgHE}$.

In Figure 4.1 below, the $k_{o}$ values are depicted for the BOL and EOL of each fuel depletion scenario. There is good agreement between the results of the four codes. In fact, the results at EOL $(60 \mathrm{MWd} / \mathrm{kg})$ are in very good agreement though the codes employ different methodologies and different nuclear data libraries. For example, SAS2H used 
ENDF/B-V data in a 238 neutron energy group library while HELIOS used ENDF/B-VI data in a 190 neutron energy group library.

In Figures 4.2 and 4.3, the detailed $\mathrm{k}_{\mathrm{o}}$ vs burnup data from the four codes are shown graphically for two pertinent cases, V2 (WG MOX) and V10 (RG MOX), respectively. In Figure 4.2, it is seen that the curves for SAS2H, TVS-M, and WIMS-ABBN start from almost the same value at zero burnup, and then diverge slightly. The TVS-M and HELIOS curves are very close for most of the burnup history. The SAS2H and WIMS-ABBN curves are similar to each other. At EOL, the results of all the codes are very close; the end points for SAS2H, HELIOS, and TVS-M are almost the same value.

An interesting detail is that the curves for SAS2H, HELIOS, and WIMS-ABBN all exhibit an initial drop or "kink" at the first burnup step while the TVS-M curve has no discontinuity. This effect is also seen in the curves in Figure 4.3. Apparently, the kink results from the simulations in SAS2H, HELIOS, and WIMS-ABBN using the specified initial concentrations from Reference 1 for ${ }^{135} \mathrm{Xe}$ and ${ }^{149} \mathrm{Sm}$ as requested in the specifications for State S1, the TVS$\mathrm{M}$ simulation actually used its internal y consistent ${ }^{135} \mathrm{Xe}$ and ${ }^{149} \mathrm{Sm}$ concentrations.

Figure 4.1. $\mathrm{k}_{\mathrm{o}}$ for $\mathrm{V} 1, \mathrm{~V} 2$, and $\mathrm{V} 10$ at fresh (BOL) and $60 \mathrm{MWd} / \mathrm{kgHE}$ (EOL) burnup.

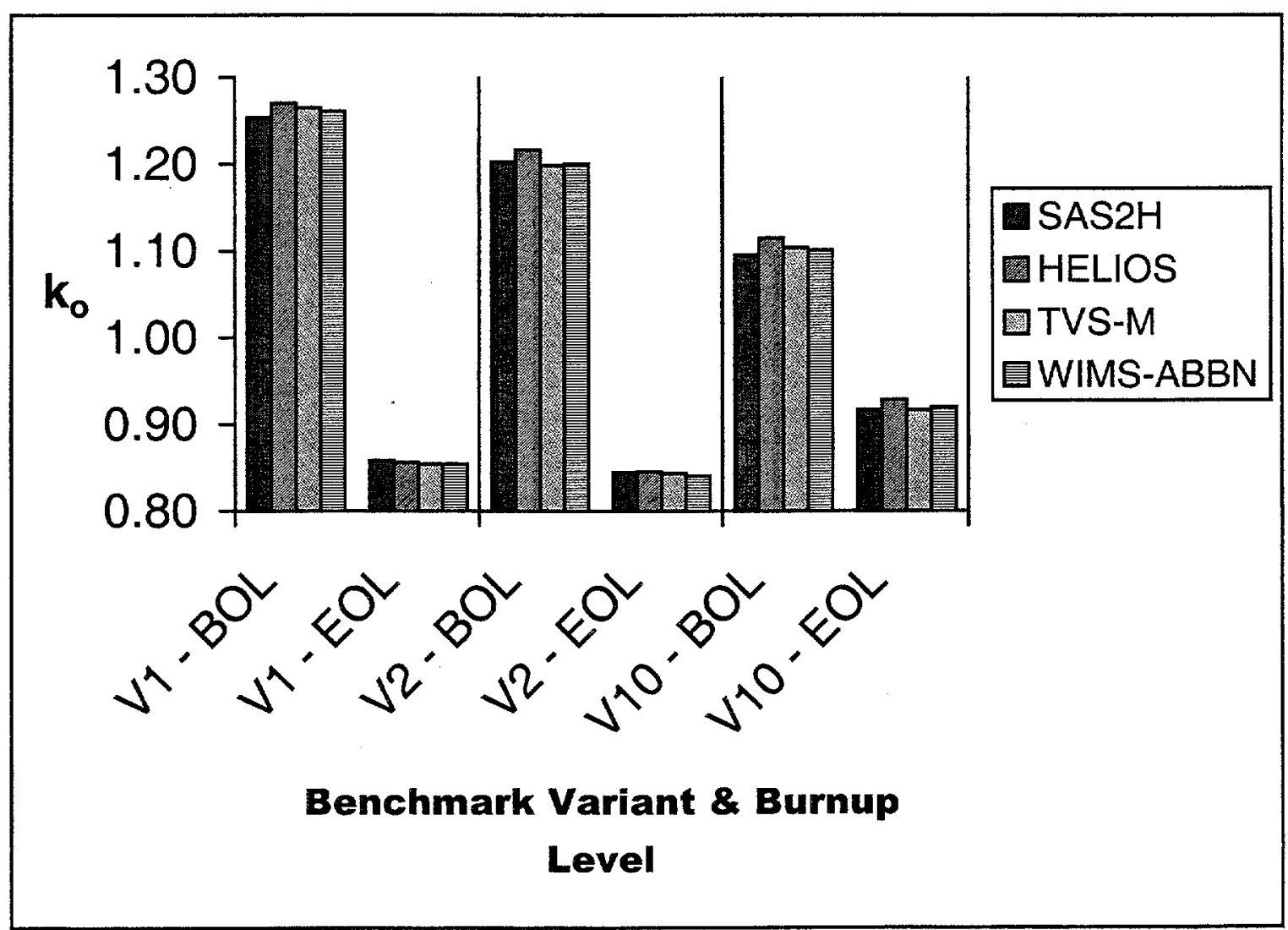




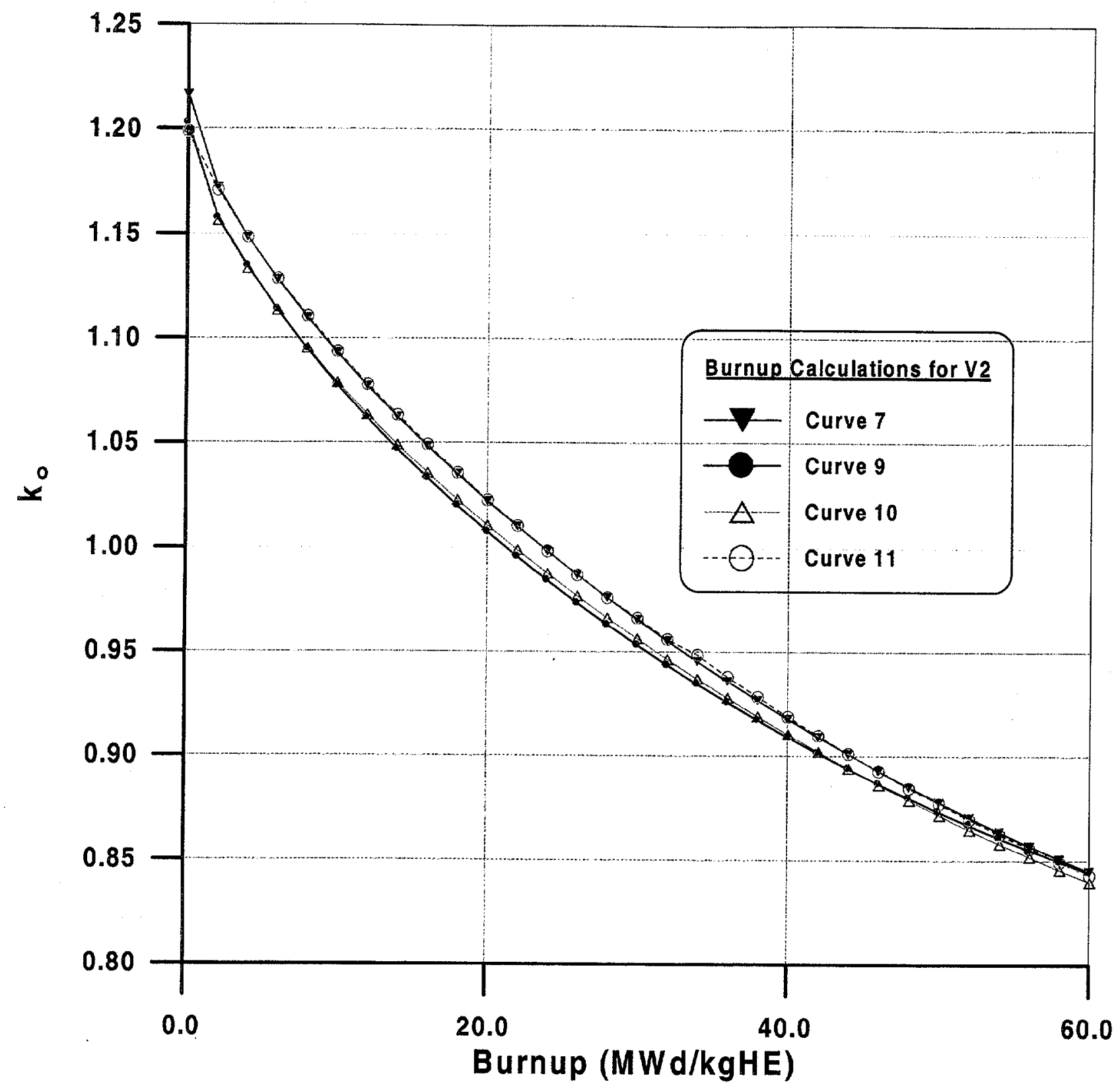

Figure 4.2. Code Comparison of $k_{o}$ vs burnup for Fuel Variant V2 (WG MOX).

Further investigation assessed the concentrations of these two important fission product poison nuclides as functions of burnup for the V2 fuel depletion case only. The results are shown in Tables 4.6 and 4.7. It is clear that at BOL the concentrations in the TVS-M simulation are considerably greater than the State $\mathrm{S} 1$ values used in the other code calculations. The given values for these concentrations are too small and definitely not consistent with the correct value for the power density and neutron flux levels in the simulations. The concentration levels undergo adjustment throughout the simulations and particularly during the first burnup step. 
Table 4.6. ${ }^{135} \mathrm{Xe}$ concentration $(\mathrm{a} / \mathrm{b}-\mathrm{cm})$ in fuel during depletion simulation for $\mathrm{V} 2$.

\begin{tabular}{cccccccc}
\hline & $\begin{array}{c}10 \\
\mathrm{MWd} / \mathrm{kg}\end{array}$ & $\mathrm{MWd} / \mathrm{kg}$ & $\begin{array}{c}20 \\
\mathrm{MWd} / \mathrm{kg}\end{array}$ & $\begin{array}{c}30 \\
\mathrm{MWd} / \mathrm{kg}\end{array}$ & $\begin{array}{c}40 \\
\mathrm{MWd} / \mathrm{kg}\end{array}$ & $\begin{array}{c}50 \\
\mathrm{MWd} / \mathrm{kg}\end{array}$ & $\begin{array}{c}60 \\
\mathrm{MWd} / \mathrm{kg}\end{array}$ \\
\hline SAS2H & $9.46 \times 10^{-9}$ & $1.55 \times 10^{-8}$ & $1.42 \times 10^{-8}$ & $1.31 \times 10^{-8}$ & $1.22 \times 10^{-8}$ & $1.14 \times 10^{-8}$ & $1.02 \times 10^{-8}$ \\
HELIOS & $9.46 \times 10^{-9}$ & $1.57 \times 10^{-8}$ & $1.42 \times 10^{-8}$ & $1.29 \times 10^{-8}$ & $1.18 \times 10^{-8}$ & $1.08 \times 10^{-8}$ & $1.01 \times 10^{-8}$ \\
WIMS-A- & $9.46 \times 10^{-9}$ & $1.55 \times 10^{-8}$ & $1.41 \times 10^{-8}$ & $1.29 \times 10^{-8}$ & $1.18 \times 10^{-8}$ & $1.09 \times 10^{-8}$ & $1.01 \times 10^{-8}$ \\
\hline TVS-M & $1.60 \times 10^{-8}$ & $1.47 \times 10^{-8}$ & $1.33 \times 10^{-8}$ & $1.20 \times 10^{-8}$ & $1.09 \times 10^{-8}$ & $1.01 \times 10^{-8}$ & $9.37 \times 10^{-9}$ \\
\hline
\end{tabular}

Table 4.7. ${ }^{149} \mathrm{Sm}$ concentration $(\mathrm{a} / \mathrm{b}-\mathrm{cm})$ in fuel during depletion simulation for $\mathrm{V} 2$.

\begin{tabular}{cccccccc}
\hline & $0 \mathrm{MWd} / \mathrm{kg}$ & $10 \mathrm{MWd} / \mathrm{kg}$ & $20 \mathrm{MWd} / \mathrm{kg}$ & $30 \mathrm{MWd} / \mathrm{kg}$ & $40 \mathrm{MWd} / \mathrm{kg}$ & $50 \mathrm{MWd} / \mathrm{kg}$ & $60 \mathrm{MWd} / \mathrm{kg}$ \\
\hline SAS2H & $7.37 \times 10^{-8}$ & $1.74 \times 10^{-7}$ & $1.74 \times 10^{-7}$ & $1.68 \times 10^{-7}$ & $1.60 \times 10^{-7}$ & $1.52 \times 10^{-7}$ & $1.31 \times 10^{-7}$ \\
HELIOS & $7.37 \times 10^{-8}$ & $1.79 \times 10^{-7}$ & $1.75 \times 10^{-7}$ & $1.66 \times 10^{-7}$ & $1.56 \times 10^{-7}$ & $1.46 \times 10^{-7}$ & $1.37 \times 10^{-7}$ \\
WIMS-A-C & $7.37 \times 10^{-7}$ & $1.80 \times 10^{-7}$ & $1.78 \times 10^{-7}$ & $1.69 \times 10^{-7}$ & $1.57 \times 10^{-7}$ & $1.45 \times 10^{-7}$ & $1.35 \times 10^{-7}$ \\
TVS-M & $1.57 \times 10^{-7}$ & $1.39 \times 10^{-7}$ & $1.20 \times 10^{-7}$ & $1.05 \times 10^{-7}$ & $9.24 \times 10^{-8}$ & $8.30 \times 10^{-8}$ & $7.57 \times 10^{-8}$ \\
\hline
\end{tabular}

Tables 4.8 and 4.9 show good agreement between the codes for the concentrations of two representative fissile nuclides ${ }^{235} \mathrm{U}$ and ${ }^{239} \mathrm{Pu}$ during the $\mathrm{V} 2$ depletion simulation. The relative differences in the net change in ${ }^{239} \mathrm{Pu}$ between BOL and EOL for SAS2H, HELIOS, TVS-M, and WIMS-ABBN are within 5\% for the four codes. The relative differences in the net change in ${ }^{235} \mathrm{U}$ for the four codes are within $\pm 1.5 \%$.

Table 4.8. ${ }^{239} \mathrm{Pu}$ concentration $(\mathrm{a} / \mathrm{b}-\mathrm{cm})$ in fuel during depletion simulation for $\mathrm{V} 2$.

\begin{tabular}{cccccccc}
\hline & $0 \mathrm{MWd} / \mathrm{kg}$ & $10 \mathrm{MWd} / \mathrm{kg}$ & $20 \mathrm{MWd} / \mathrm{kg}$ & $30 \mathrm{MWd} / \mathrm{kg}$ & $40 \mathrm{MWd} / \mathrm{kg}$ & $50 \mathrm{MWd} / \mathrm{kg}$ & $60 \mathrm{MWd} / \mathrm{kg}$ \\
\hline SAS2H & $6.59 \times 10^{-4}$ & $5.16 \times 10^{-4}$ & $4.08 \times 10^{-4}$ & $3.30 \times 10^{-4}$ & $2.76 \times 10-4$ & $2.42 \times 10^{-4}$ & $2.20 \times 10^{-4}$ \\
HELIOS & $6.59 \times 10^{-4}$ & $5.12 \times 10^{-4}$ & $3.97 \times 10^{-4}$ & $3.13 \times 10^{-4}$ & $2.55 \times 10^{-4}$ & $2.17 \times 10^{-4}$ & $1.93 \times 10^{-4}$ \\
WIMS-A-C & $6.59 \times 10^{-4}$ & $5.14 \times 10^{-4}$ & $4.04 \times 10^{-4}$ & $3.22 \times 10^{-4}$ & $2.65 \times 10^{-4}$ & $2.28 \times 10^{-4}$ & $2.04 \times 10^{-4}$ \\
\hline TVS-M & $6.59 \times 10^{-4}$ & $5.16 \times 10^{-4}$ & $4.05 \times 10^{-4}$ & $3.22 \times 10^{-4}$ & $2.64 \times 10^{-4}$ & $2.25 \times 10^{-4}$ & $2.01 \times 10^{-4}$ \\
\hline
\end{tabular}

Table 4.9. ${ }^{235} \mathrm{U}$ concentration $(\mathrm{a} / \mathrm{b}-\mathrm{cm})$ in fuel during depletion simulation for $\mathrm{V} 2$.

\begin{tabular}{cccccccc}
\hline & $0 \mathrm{MWd} / \mathrm{kg}$ & $10 \mathrm{MWd} / \mathrm{kg}$ & $20 \mathrm{MWd} / \mathrm{kg}$ & $30 \mathrm{MWd} / \mathrm{kg}$ & $40 \mathrm{MWd} / \mathrm{kg}$ & $50 \mathrm{MWd} / \mathrm{kg}$ & $60 \mathrm{MWd} / \mathrm{kg}$ \\
\hline \multirow{2}{*}{ SAS2H } & $3.84 \times 10^{-5}$ & $3.17 \times 10^{-5}$ & $2.55 \times 10^{-5}$ & $2.01 \times 10^{-5}$ & $1.55 \times 10^{-5}$ & $1.17 \times 10^{-5}$ & $8.69 \times 10^{-6}$ \\
HELIOS & $3.84 \times 10^{-5}$ & $3.17 \times 10^{-5}$ & $2.56 \times 10^{-5}$ & $2.01 \times 10^{-5}$ & $1.53 \times 10^{-5}$ & $1.14 \times 10^{-5}$ & $8.24 \times 10^{-6}$ \\
& $3.84 \times 10^{-5}$ & $3.17 \times 10^{-5}$ & $2.56 \times 10^{-5}$ & $2.01 \times 10^{-5}$ & $1.53 \times 10^{-4}$ & $1.14 \times 10^{-5}$ & $8.31 \times 10^{-5}$ \\
\hline TVS-M & $3.84 \times 10^{-5}$ & $3.17 \times 10^{-5}$ & $2.55 \times 10^{-5}$ & $2.00 \times 10^{-5}$ & $1.52 \times 10^{-5}$ & $1.12 \times 10^{-5}$ & $8.09 \times 10^{-6}$ \\
\hline
\end{tabular}




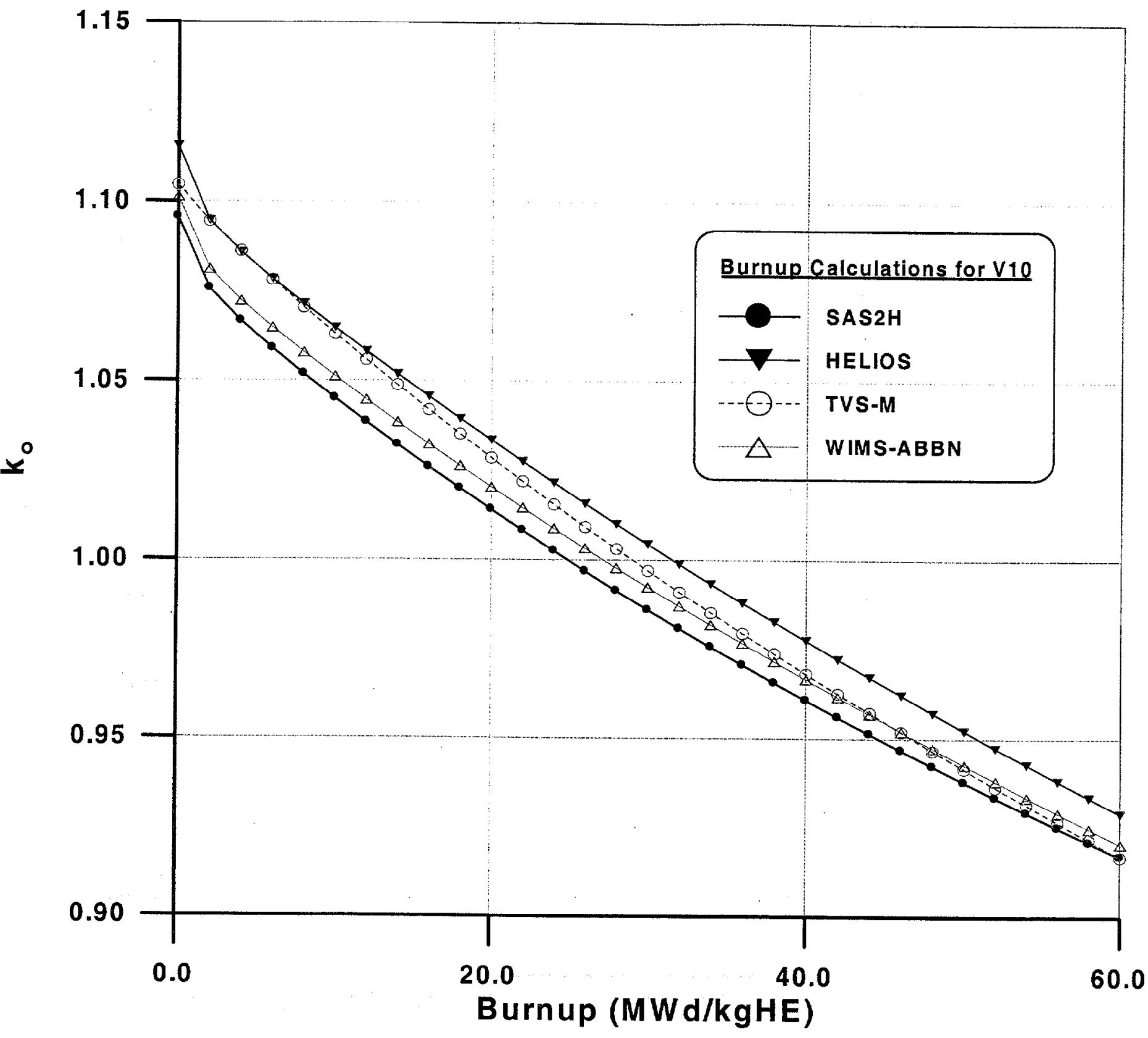

Figure 4.3. Code Comparison of $k_{\mathrm{o}}$ vs burnup for Fuel Variant V10 (RG MOX).

Figure 4.3 shows the $k_{o}$ vs burnup curves for the four codes for the V10 (RG MOX) depletion case. As seen in Figure 4.1, the difference in $\mathrm{k}_{\mathrm{o}}$ between BOL and EOL is smaller for the V10 case than the V2 case, thus the relative overall spread between the four code curves is about the same as in Figure 4.2. For the RG MOX depletion simulation, the curves for SAS2H, TVS-M, and WIMS-ABBN tend to converge at EOL. The initial kink in the SAS2H, HELIOS, and WIMS-ABBN curves is the same effect discussed above. An interesting observation is that the curves for SAS2H, WIMS-ABBN, and HELIOS $k_{0}$ vs burnup data are nearly parallel over the entire burnup history; thus, their slopes are almost the same. The relatively constant displacement of these three curves may be the result of the nuclear data for a particular nuclide in the fuel composition. 


\section{SUMMARY AND CONCLUSIONS}

There is general agreement between the calculated values for $k_{\text {eff }}, k_{0}$, and $k_{\text {inf }}$ between SAS2H, HELIOS, MCU, and TVS-M for all the fresh fuel (zero-burnup) VVER-1000 pin-cell benchmark cases. SAS2H calculations have lower $\mathrm{k}_{\text {inf }}$ values $(\sim 1.0-1.5 \%$ reactivity) than HELIOS. On the other hand, $k_{\text {eff }}$ values are slightly larger for SAS2H results than for HELIOS (by about $1.0 \%$ reactivity). Despite differences in the values of absolute multiplication factors, there is good agreement in the values of the reactivity changes between the states.

The SCALE-4.3 control sequence module SAS2H, with its connection to ORIGEN-S depletion code, was used in the simulation of three fuel depletion cases. As verification of the SAS2H results, SCALE-4.3/CSAS cases were run for the same zero-burnup benchmark cases with perfect agreement.

The results of fuel depletion simulations performed with SAS2H for the three cases (V1, $\mathrm{V} 2$, and V10, in State S1) are in good general agreement with the results from HELIOS, WIMS-ABBN, and TVS-M. The curves for $\mathrm{k}_{\mathrm{o}}$ vs burnup for the four codes show a small kink in the first burnup step that is caused by the ${ }^{135} \mathrm{Xe}$ and ${ }^{149} \mathrm{Sm}$ concentrations in the initial fuel compositions in the SAS2H, HELIOS, and WIMS-ABBN calculations using the specified (but too small) concentrations from Reference 1. Overall, the $\mathrm{k}_{\mathrm{o}}$ vs burnup curves for the four codes for the fuel depletion simulations show similar trends.

Despite the different code methodologies and nuclear data, there is good agreement between the four codes used in the depletion simulations (SCALE-4.3/SAS2H, HELIOS, WIMS-ABBN, and TVS-M). The results from the codes used for the zero-burnup (nondepletion) pin-cell benchmark cases (SCALE-4.3/SAS2H, HELIOS, MCU-RFFI/A, and TVS$\mathrm{M})$ are also in good agreement when identical simulations were performed.

The good general agreement between the depletion and non-depletion VVER-1000 pincell benchmark cases between SCALE-4.3/SAS2H and HELIOS serves as an additional verification of the HELIOS code for use in modeling VVER-1000 MOX cases. In addition, the comparison of SCALE-4.3/SAS2H and HELIOS results from ORNL with the results of the Russian codes MCU-RFFV/A, TVS-M, and WIMS-ABBN is important as a good gauge of the agreement of the various codes and nuclear data. 


\section{REFERENCES}

1. Neutronics Benchmarks for the Utilization of Mixed-Oxide Fuel: Joint U.S./Russian Progress Report for Fiscal Year 1997, Volume 3 - Calculations Performed in Russia, ORNLTM-13603/V3, Lockheed Martin Energy Research Corp., Oak Ridge National Laboratory, June 1998.

2. SCALE: A Modular Code System for Performing Standardized Computer Analyses for Licensing Evaluation, NUREG/CR-0200, Rev. 5 (ORNL/NUREG/CSD-2R5), Vols. I, II, and III, March 1997. Available from Radiation Safety Information Computational Center at Oak Ridge National Laboratory as CCC-545.

3. J.C. Gehin, C. Dourougie, M.B. Emmett, R.A. Lillie, "Analysis of Weapons-Grade MOX VVER-1000 Benchmarks with HELIOS and KENO", ORNL/TM-1999/78, July 1999.

4. J.J. Casal, R.J.J. Stamml'er, E.A. Villarino, and A.A. Ferri, "HELIOS: Geometric Capabilities of a New Fuel-Assembly Program", Proceedings of International Topical Meeting on Advances in Mathematics, Computations, and Reactor Physics", Pittsburgh, Pennsylvania, April 28-May 2, 1991, Vol.2, p.10.2.1 1-13.

5. E.A. Villarino, R.J.J. Stamml'er and A.A. Ferri, and J.J. Casal, "HELIOS: Angularly Dependent Collision Probabilities", Nuclear Science and Engineering, Vol.112, 16-31 (1992)

6. V.D. Sidorenko, et al, "Spectral Code TVS-M for Calculation of Characteristics of Cells, Supercells and Fuel Assemblies of VVER-Type Reactors", Fifth Symposium of the AER, Dobogoko, Hungary, October 15-20, 1995. 


\section{APPENDIX A. SAMPLE SAS2H INPUT DATA FILE - CASE V1, S1 (LEU UO $\left.{ }_{2}\right)$}

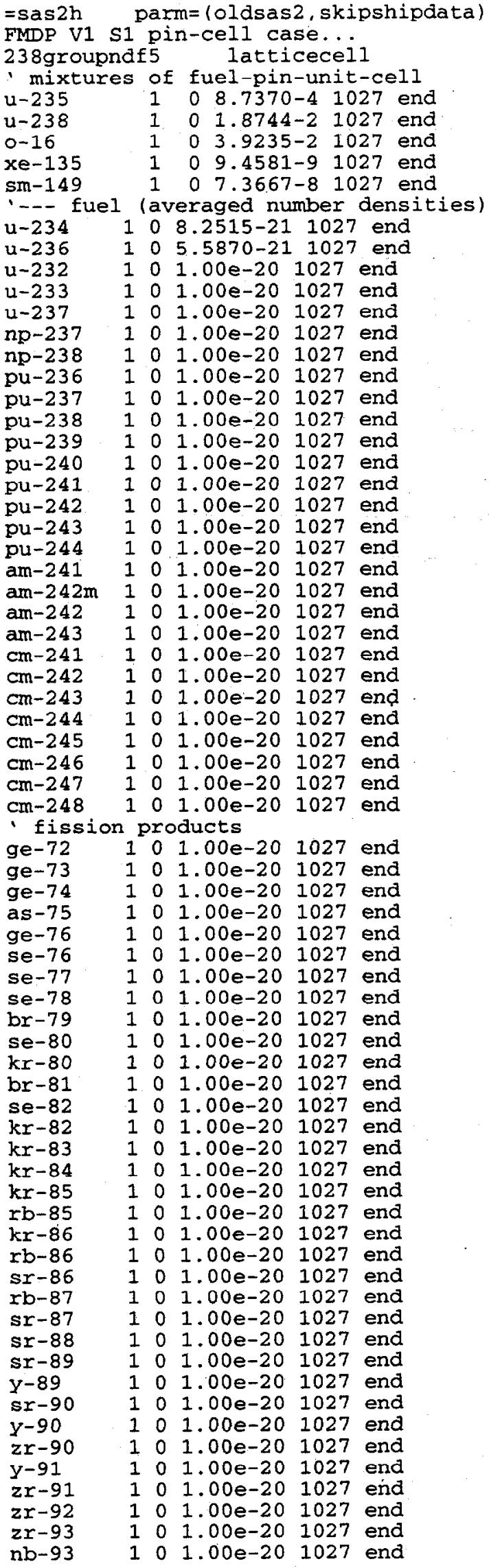

zr-94 $\quad 1001.00 e-201027$ end $\mathrm{nb}-94 \quad 101.00 \mathrm{e}-201027$ end $z r-95 \quad 1001.00 e-201027$ end $\mathrm{nb}-95 \quad 1001.00 \mathrm{e}-201027$ end mo-95 $101.00 e-201027$ end zr-96 $101.00 e-201027$ end mo-96 $101.00 \mathrm{e}-201027$ end mo-97 10 1.00e-20.1027 end mo-98 $1001.00 e-201027$ end mo-99 $1001.00 e-201027$ end tc-99 $101.00 e-201027$ end ru-99 $100.00 e-201027$ end mo-100 $10 \quad 1.00 e-201027$ end ru-100 $101.00 e-201027$ end ru-101 10 1.00e-20 1027 end ru-102 $101.00 e-201027$ end pd-102 $1001.00 e-201027$ end ru-103 I $011.00 \mathrm{e}-201027$ end $\mathrm{rh}-103 \quad 10 \mathrm{1} 1.00 \mathrm{e}-201027$ end ru-104 10 1.00e-20 1027 end pd-104 $\quad 1 \quad 0 \quad 1.00 e-201027$ end ru-105 $1001.00 e-201027$ end rh-105 $101.00 e-201027$ end pd-105 $101.00 \mathrm{e}-201027$ end ru-106 $1001.00 e-201027$ end pd-106 $1001.00 \mathrm{e}-201027$ end pd-107 $1001.00 e-201027$ end ag-107 $10.1 .00 e-20 \quad 1027$ end pd-108 $1001.00 e-201027$ end cd-108 $1001.00 e-201027$ end ag-109 $1001.00 e-201027$ end pd-110 $1001.00 \mathrm{e}-201027$ end cd-110 $1001.00 e-201027$ end ag-111 $1001.00 \mathrm{e}-201027$ end cd-111 $1001.00 e-201027$ end cd-112 $101.00 \mathrm{e}-201027$ end cd-113 $1001.00 \mathrm{e}-201027$ end in-113 $10.1 .00 \mathrm{e}-201027$ end cd-114 1 o $1.00 e-201027$ end sn-114 10 1.00e-20 1027 end $\mathrm{cd}-115 \mathrm{~m} \quad 1001.00 \mathrm{e}-201027$ end in-115 100 1.00e-20 1027 end sn-115 $1001.00 e-201027$ end cd-116 $1001.00 \mathrm{e}-201027$ end sn-116 $1001.00 \mathrm{e}-201027$ end sn-117 $101.00 e-201027$ end sn-118 $1001.00 e-201027$ end sn-119 $1001.00 e-201027$ end sn-120 $101.00 e-201027$ end sb-121 I 0 1.00e-20 1027 end sn-122 $1001.00 e-201027$ end te-122 $101.00 e-201027$ end sn-123 $1001.00 e-201027$ end sb-123 $101.00 e-201027$ end te-123 $1001.00 e-201027$ end sn-124 $1001.00 e-201027$ end sb-124 $1001.00 e-201027$ end te-124 $101.00 e-201027$ end sn-125 $101.00 e-201027$ end sb-125 $1001.00 e-201027$ end te-125 $1001.00 e-201027$ end sn-126 $101.00 e-20 \quad 1027$ end sb-126 $1001.00 e-201027$ end te-126 $101.00 e-201027$ end xe-126 10 1.00e-20 1027 end te $-127 \mathrm{~m} \quad 1 \quad 0 \quad 1.00 e-20.1027$ end

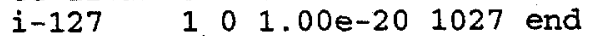
te-128 1 o $1.00 e-201027$ end $x e-128 \quad 1 \quad 0 \quad 1.00 e-201027$ end te-129m $101.00 \mathrm{e}-201027$ end

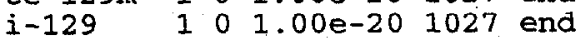




\begin{tabular}{|c|c|c|c|c|}
\hline 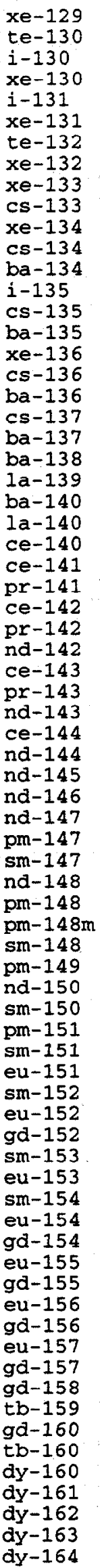 & $\begin{array}{ll}1 & 0 \\
1 & 0 \\
1 & 0 \\
1 & 0 \\
1 & 0 \\
1 & 0 \\
1 & 0 \\
1 & 0 \\
1 & 0 \\
1 & 0 \\
1 & 0 \\
1 & 0 \\
1 & 0 \\
1 & 0 \\
1 & 0 \\
1 & 0 \\
1 & 0 \\
1 & 0 \\
1 & 0 \\
1 & 0 \\
1 & 0 \\
1 & 0 \\
1 & 0 \\
1 & 0 \\
1 & 0 \\
1 & 0 \\
1 & 0 \\
1 & 0 \\
1 & 0 \\
1 & 0 \\
1 & 0 \\
1 & 0 \\
1 & 0 \\
1 & 0 \\
1 & 0 \\
1 & 0 \\
1 & 0 \\
1 & 0 \\
1 & 0 \\
1 & 0 \\
1 & 0 \\
1 & 0 \\
1 & 0 \\
1 & 0 \\
1 & 0 \\
1 & 0 \\
1 & 0 \\
1 & 0 \\
1 & 0 \\
1 & 0 \\
1 & 0 \\
1 & 0 \\
1 & 0 \\
1 & 0 \\
1 & 0 \\
1 & 0 \\
1 & 0 \\
1 & 0 \\
1 & 0 \\
1 & 0 \\
1 & 0 \\
1 & 0 \\
1 & 0 \\
1 & 0 \\
1 & 0 \\
1 & 0 \\
1 & 0 \\
1 & 0 \\
& 0 \\
& 0\end{array}$ & $\begin{array}{l}1.00 \mathrm{e}-20 \\
1.00 \mathrm{e}-20 \\
1.00 \mathrm{e}-20 \\
1.00 \mathrm{e}-20 \\
1.00 \mathrm{e}-20 \\
1.00 \mathrm{e}-20 \\
1.00 \mathrm{e}-20 \\
1.00 \mathrm{e}-20 \\
1.00 \mathrm{e}-20 \\
1.00 \mathrm{e}-20 \\
1.00 \mathrm{e}-20 \\
1.00 \mathrm{e}-20 \\
1.00 \mathrm{e}-20 \\
1.00 \mathrm{e}-20 \\
1.00 \mathrm{e}-20 \\
1.00 \mathrm{e}-20 \\
1.00 \mathrm{e}-20 \\
1.00 \mathrm{e}-20 \\
1.00 \mathrm{e}-20 \\
1.00 \mathrm{e}-20 \\
1.00 \mathrm{e}-20 \\
1.00 \mathrm{e}-20 \\
1.00 \mathrm{e}-20 \\
1.00 \mathrm{e}-20 \\
1.00 \mathrm{e}-20 \\
1.00 \mathrm{e}-20 \\
1.00 \mathrm{e}-20 \\
1.00 \mathrm{e}-20 \\
1.00 \mathrm{e}-20 \\
1.00 \mathrm{e}-20 \\
1.00 \mathrm{e}-20 \\
1.00 \mathrm{e}-20 \\
1.00 \mathrm{e}-20 \\
1.00 \mathrm{e}-20 \\
1.00 \mathrm{e}-20 \\
1.00 \mathrm{e}-20 \\
1.00 \mathrm{e}-20 \\
1.00 \mathrm{e}-20 \\
1.00 \mathrm{e}-20 \\
1.00 \mathrm{e}-20 \\
1.00 \mathrm{e}-20 \\
1.00 \mathrm{e}-20 \\
1.00 \mathrm{e}-20 \\
1.00 \mathrm{e}-20 \\
1.00 \mathrm{e}-20 \\
1.00 \mathrm{e}-20 \\
1.00 \mathrm{e}-20 \\
1.00 \mathrm{e}-20 \\
1.00 \mathrm{e}-20 \\
1.00 \mathrm{e}-20 \\
1.00 \mathrm{e}-20 \\
1.00 \mathrm{e}-20 \\
1.00 \mathrm{e}-20 \mathrm{e}-20 \\
1.00 \mathrm{e}-20 \mathrm{e}-20 \\
1.00 \mathrm{e}-20 \\
1.00 \mathrm{e}-20 \mathrm{e}-20 \\
1.00 \mathrm{e}-20 \\
1.00 \mathrm{e}-20 \\
1.00 \mathrm{e}-20\end{array}$ & $\begin{array}{l}1027 \\
1027 \\
1027 \\
1027 \\
1027 \\
1027 \\
1027 \\
1027 \\
1027 \\
1027 \\
1027 \\
1027 \\
1027 \\
1027 \\
1027 \\
1027 \\
1027 \\
1027 \\
1027 \\
1027 \\
1027 \\
1027 \\
1027 \\
1027 \\
1027 \\
1027 \\
1027 \\
1027 \\
1027 \\
1027 \\
1027 \\
1027 \\
1027 \\
1027 \\
1027 \\
1027 \\
1027 \\
1027 \\
1027 \\
1027 \\
1027 \\
1027 \\
1027 \\
1027 \\
1027 \\
1027 \\
1027 \\
1027 \\
1027 \\
1027 \\
1027 \\
1027 \\
1027 \\
1027 \\
1027 \\
1027 \\
1027 \\
1027 \\
1027 \\
1027 \\
1027 \\
1027\end{array}$ & $\begin{array}{l}\text { end } \\
\text { end } \\
\text { end } \\
\text { end } \\
\text { end } \\
\text { end } \\
\text { end } \\
\text { end } \\
\text { end } \\
\text { end } \\
\text { end } \\
\text { end } \\
\text { end } \\
\text { end } \\
\text { end } \\
\text { end } \\
\text { end } \\
\text { end } \\
\text { end } \\
\text { end } \\
\text { end } \\
\text { end } \\
\text { end } \\
\text { end } \\
\text { end } \\
\text { end } \\
\text { end } \\
\text { end } \\
\text { end } \\
\text { end } \\
\text { end } \\
\text { end } \\
\text { end } \\
\text { end } \\
\text { end } \\
\text { end } \\
\text { end } \\
\text { end } \\
\text { end } \\
\text { end } \\
\text { end } \\
\text { end } \\
\text { end } \\
\text { end } \\
\text { end } \\
\text { end } \\
\text { end } \\
\text { end } \\
\text { end } \\
\text { end } \\
\text { end } \\
\text { end } \\
\text { end } \\
\text { end } \\
\text { end } \\
\text { end } \\
\text { end } \\
\text { end } \\
\text { end } \\
\text { end } \\
\text { end } \\
\text { end } \\
\text { end } \\
\text { end } \\
\text { end } \\
\text { end } \\
\text { end } \\
\text { end } \\
\text { end } \\
\text { end } \\
\text { end } \\
\text { end } \\
\text { end } \\
\text { end } \\
\text { end } \\
\text { end }\end{array}$ \\
\hline
\end{tabular}

ho-165 $101.00 e-201027$ ender-166 $01.00 e-201027$ end

er $-167 \quad 101.00 \mathrm{e}-20 \quad 1027$ end

- end of fission products

$2 r \quad 2 \quad 04.23-2 \quad 579$ end

h $304.783-2 \quad 579$ end

$0-16$ 3 0 2.391-2 579 end

$b-10 \quad 3 \quad 0 \quad 4.7344-6 \quad 579$ end

b-11 $3001.9177-5 \quad 579$ end

end comp

fuel-pin-cell geometry:

triangpitch $1.275 \quad 0.772 \quad 130.91642$ end

more data $d z=0 . d y=57.357 \quad b k l=0.0$

szf $=.75$ isn $=16$ eps $=.00001$

ptc $=.00001$ end

assembly and cycle parameters:

npin/assm $=1$ fuelngth $=275.6454$ ncycles $=32$ nlib/cyc $=1$

printlevel $=6$

lightel=1

power $=.041910912$ burn $=0.00001$ down $=0$ end power $=.041910912$ burn=23.8601 down=0 end power $=.041910912$ burn $=47.7203$ down $=0$ end power $=.041910912$ burn $=47.7203$ down $=0$ end power $=.041910912$ burn $=47.7203$ down $=0$ end power $=.041910912$ burn $=47.7203$ down $=0$ end power $=.041910912$ burn $=47.7203$ down $=0$ end power $=.041910912$ burn $=47.7203$ down $=0$ end power $=.041910912$ burn $=47.7203$ down $=0$ end power $=.041910912$ burn $=47.7203$ down $=0$ end power $=.041910912$ burn $=47.7203$ down $=0$ end power $=.041910912$ burn $=47.7203$ down $=0$ end power $=.041910912$ burn $=47.7203$ down $=0$ end power $=.041910912$ burn $=47.7203$ down $=0$ end power $=.041910912$ burn $=47.7203$ down $=0$ end power $=.041910912$ burn=47.7203 down=0 end power $=.041910912$ burn $=47.7203$ down $=0$ end power $=.041910912$ burn=47.7203 down=0 end power $=.041910912$ burn $=47.7203$ down $=0$ end power $=.041910912$ burn $=47.7203$ down $=0$ end power $=.041910912$ burn $=47.7203$ down $=0$ end power $=.041910912$ burn $=47.7203$ down $=0$ end power $=.041910912$ burn $=47.7203$ down $=0$ end power $=.041910912$ burn $=47.7203$ down $=0$ end power $=.041910912$ burn=47.7203 down=0 end power $=.041910912$ burn $=47.7203$ down $=0$ end power $=.041910912$ burn=47.7203 down $=0$ end power $=.041910912$ burn $=47.7203$ down $=0$ end power $=.041910912$ burn $=47.7203$ down $=0$ end power $=.041910912$ burn $=47.7203$ down $=0$ end power $=.041910912$ burn $=47.7203$ down $=0$ end power $=.041910912$ burn $=47.7203$ down=0 end

$2 r \quad 0.33820827$

end 


\section{APPENDIX B. SAMPLE SAS2H INPUT DATA FILE - CASE V2, S1 (WG MOX)}

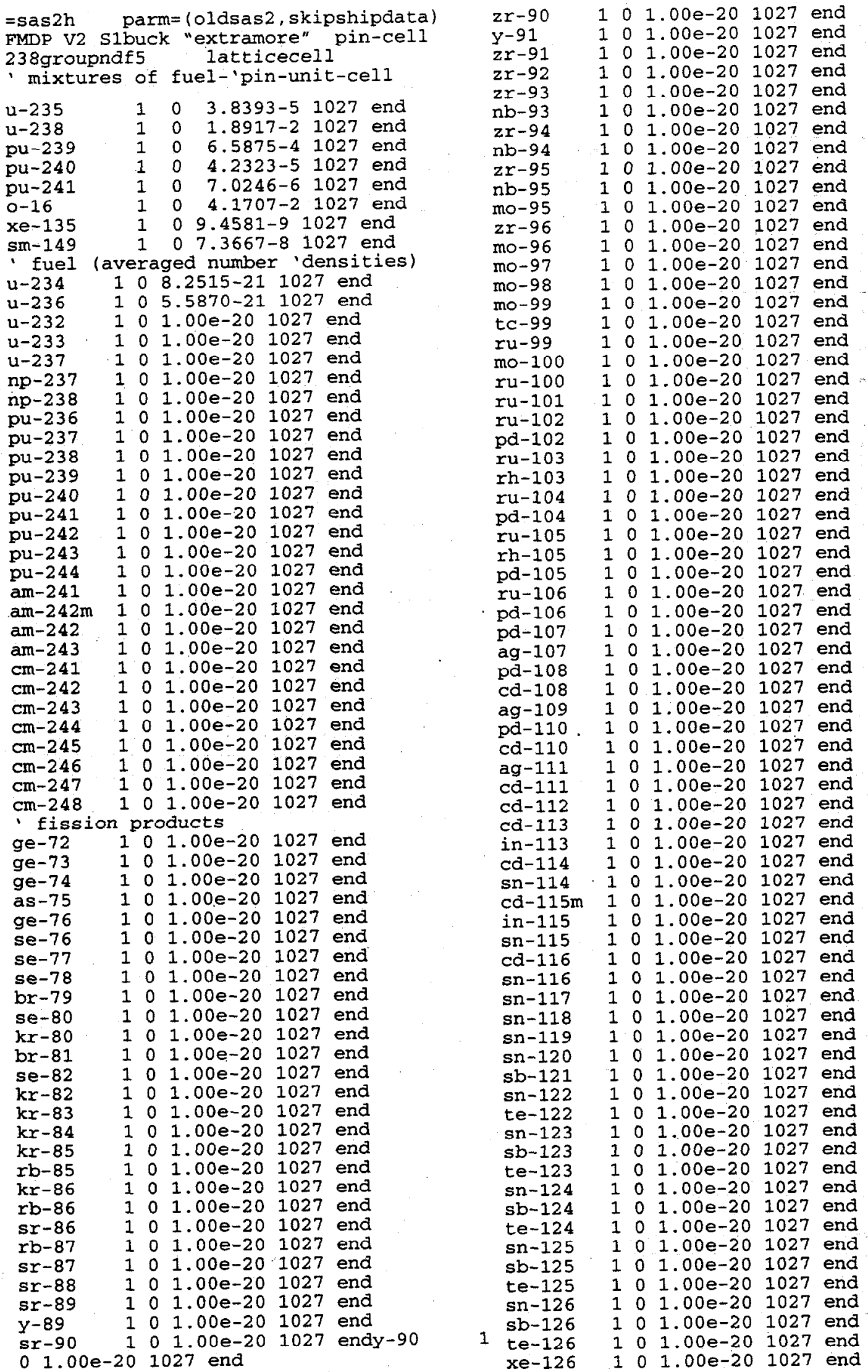


te-127m $101.00 e-201027$ end $i-127 \quad 1 \quad 0 \quad 1.00 e-201027$ end te-128 $\quad 1 \quad 0 \quad 1.00 e-20 \quad 1027$ end $x e-128 \quad 1 \quad 0 \quad 1.00 e-20 \quad 1027$ end te-129m $10.1 .00 e-201027$ end i-129 10 1.00e-20 1027 end $x e-129 \quad 10 \quad 1.00 e-201027$ end te $-130 \quad 101.00 e-201027$ end $i-130 \quad 1001.00 e-201027$ end $x e-130 \quad 1001.00 e-201027$ end $i-131 \quad 1 \quad 0 \quad 1.00 e-201027$ end $x e-131 \quad 101.00 e-201027$ end te $-132 \quad 1 \quad 0 \quad 1.00 e-201027$ end $x e-132: 101.00 \mathrm{e}-20,1027$ end $x e-133 \quad 101.00 e-201027$ end cs-133 10 1.00e-20 1027 end xe-134 $1001.00 e-201027$ end cs-134 $\quad 1 \quad 0 \quad 1.00 e-201027$ end ba-134 $10.1 .00 e-201027$ end i-135 $10.1 .00 \mathrm{e}-201027$ end cs-135 $10.1 .00 e-201027$ end $\mathrm{ba}-135 \quad 1001.00 \mathrm{e}-201027$ end xe-136 $101.00 e-201027$ end cs-136 1 o $1.00 e-201027$ end ba-136 10 1.00e-20 1027 end cs-137 $1001.00 e-201027$ end ba-137 $1001.00 e-201027$ end ba-138 $1001.00 e-201027$ end $1 a-139 \quad 1001.00 e-201027$ end ba-140 $1001.00 e-201027$ end 1a-140 100 1.00e-20 1027 end ce-140 $1001.00 \mathrm{e}-201027$ end ce-141 $101.00 e-201027$ end pr-141 $101.00 e-201027$ end ce-142 $101.00 e-201027$ end pr-142 $101.00 e-201027$ end nd-142 $10.1 .00 e-201027$ end $\mathrm{ce}-143 \quad 101.00 \mathrm{e}-201027$ end pr-143 $\quad 1001.00 e-201027$ end nd-143 $1001.00 e-201027$ end ce-144 1 . $011.00 \mathrm{e}-201027$ end nd-144 $1001.00 e-201027$ end nd-145 10 1.00e-20 1027 end nd-146 10 1.00e-20 1027 end nd-147 1001.00 e-20 1027 end pm-147 10 1.00e-20 1027 end sm-147 $10.1 .00 e-201027$ end nd-148 $101.00 \mathrm{e}-201027$ end pm-148 $101.00 e-201027$ end pm-148m $101.00 \mathrm{e}-201027$ end sm-148 1 . $01.00 e-201027$ end pm-149 $101.00 \mathrm{e}-201027$ end nd-150 $101.00 \mathrm{e}-201027$ end sm-150 $1001,00 e-201027$ end pm-151 10 1.00e-20 1027 end sm-151 $101.00 e-201027$ end eu-151 $101.00 e-201027$ end sm-152 $1.01 .00 e-201027$ end eu-152 1 o $1.00 \mathrm{e}-201027$ end gd-152 10 1.00e-20 1027 end sm-153 $1001.00 e-201027$ end eu-153 $101.00 e-201027$ end sm-154 $101.00 e-201027$ end eu-154 1 o $1.00 \mathrm{e}-201027$ end gd-154 10 1.00e-20 1027 end eu-155 $101.00 e-201027$ end gd-155 $101.00 e-201027$ end eu-156 $101.00 \mathrm{e}-201027$ end gd-156 $101.00 e-201027$ end eu-157 $101.00 \mathrm{e}-201027$ end gd-157 $101.00 e-201027$ end gd-158 $1001.00 e-201027$ end tb-159 $1001.00 \mathrm{e}-201027$ end gd-160 $1001.00 e-201027$ end tb-160 10 1.00e-20 1027 end $d y-160 \quad 1001.00 e-20 \quad 1027$ end

dy-161 $10.1 .00 e-20.1027$ end

dy-162 10 1.00e-20 1027 end

$d y-163 \quad 1001.00 e-20,1027$ end

$d y-164 \quad 1001.00 e-201027$ end

ho-165 $101.00 e-201027$ end

er $-166 \quad 101.00 \mathrm{e}-201027$ end

er-167 $101.00 \mathrm{e}-201027$ end

$\because$ end of fission products

zr. $\quad 2$ o $4.23-2 \quad 579$ end

$h \quad 304.783-2579$ end

$0-16 \quad 3 \quad 02.391-2 \quad 579$ end

$b-10 \quad 3 \quad 04.7344-6579$ end

$b-11 \quad 3 \quad 01.9177-5 \quad 579$ end

end comp

fuel-pin-cell geometry:

triangpitch 1.2750 .772130 .91642 end

more data $\mathrm{dz}=0 . \mathrm{dy}=57.357 \mathrm{bkl}=0.0$

sz $f=.75$ is $=16$

eps $=.00001$ ptc $=.00001$ end

assembly and cycle parameters:

npin/assm $=1$ fuelngth $=274.81039$

ncycles $=32 \mathrm{nlib} / \mathrm{cyc}=1$

Printlevel $=6$

lightel $=1$

power $=.0417837$ burn $=0.00001$ down $=0$ end

power $=.0417837$ burn $=23.93278$ down $=0$ end

power $=.0417837$ burn $=47.86556$ down $=0$ end power $=.0417837$ burn $=47.86556$ down $=0$ end power $=.0417837$ burn $=47.86556$ down $=0$ end power $=.0417837$ burn $=47.86556$ down $=0$ end power $=.0417837$ burn $=47.85556$ down $=0$ end power $=.0417837$ burn $=47.86556$ down $=0$ end power $=.0417837$ burn $=47.86556$ down $=0$ end power $=.0417837$ burn $=47.86556$ down $=0$ end power $=.0417837$ burn $=47.86556$ down $=0$ end power $=.0417837$ burn $=47.86556$ down $=0$ end power $=.0417837$ burn $=47.86556$ down $=0$ end power $=.0417837$ burn $=47.86556$ down $=0$ end power $=.0417837$ burn $=47.86556$ down $=0$ end power $=.0417837$ burn $=47.86556$ down $=0$ end power $=.0417837$ burn $=47.86556$ down $=0$ end power $=.0417837$ burn $=47.86556$ down $=0$ end power $=.0417837$ burn $=47.86556$ down $=0$ end power $=.0417837$ burn $=47.86556$ down $=0$ end power $=.0417837$ burn $=47.86556$ down $=0$ end power $=.0417837$ burn $=47.86556$ down $=0$ end power $=.0417837$ burn $=47.86556$ down $=0$, end power $=.0417837$ burn $=47.86556$ down $=0$ end power $=.0417837$ burn $=47.86556$ down $=0$ end power $=.0417837$ burn $=47.86556$ down $=0$ end power $=.0417837$ burn $=47.86556$ down $=0$ end power $=.0417837$ burn $=47.86556$ down $=0$ end power $=.0417837$ burn $=47.86556$ down $=0$ end power $=.0417837$ burn $=47.86556$ down $=0$ end power $=.0417837$ burn $=47.86556$ down $=0$ end power $=.0417837$ burn $=47.86556$ down $=0$ end 2r 0.33719 end 
APPENDIX C. SAMPLE SAS2H INPUT DATA FILE - CASE V10, S1 (RG MOX)

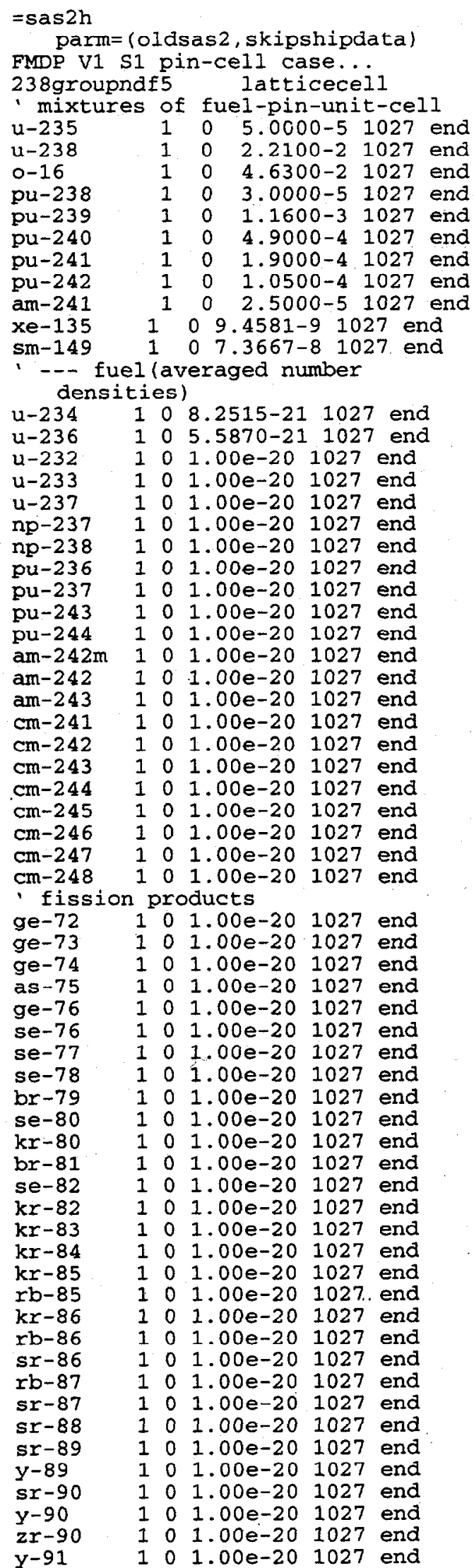

$z x-91$

$\mathrm{zr}-92$

$z r-93$

no-93

zr -94

$\mathrm{nb}-94$

zr -95

$\mathrm{nb}-95$

mo-95

$z r-96$

mo-96

mo-97

mo-98

mo-99

tc -99

ru-99

mo-100

ru-100

ru-101

ru-102

pd-102

ru-103

rh-103

ru-104

pa-104

ru-105

rh-105

pd-105

ru-106

pd-106

pd-107

ag-107

pd-108

cd-108

ag-109

pd-110

cd-110

ag-111

cd-111

cd-112

cd-113

in -113

cd-114

sn-114

cd-115m

in -115

sn-115

cd-116

sn-116

sn- 117

sn-118

sn-119

sn-120

sb- 121

sn-122

te -122

sn-123

sb-123

te-123

sn-124

sb-124

te-124

sn-125

sb-125

te-125

sn-126

sb-126

te-126

$\mathrm{xe}-126$

te-127m

i-127
$101.00 \mathrm{e}-201027$ end $101.00 \mathrm{e}-201027$ end $10.1 .00 e-201027$ end

$101.00 \mathrm{e}-201027$ end

$101.00 \mathrm{e}-20 \quad 1027$ end

$101.00 \mathrm{e}-201027$ end

$1001.00 \mathrm{e}-201027$ end

$101.00 \mathrm{e}-201027$ end

$101.00 e-201027$ end

$1001.00 \mathrm{e}-201027$ end

$101.00 e-201027$ end

$101.00 e-201027$ end

$101.00 \mathrm{e}-201027$ end

$101.00 e-201027$ end

$101.00 \mathrm{e}-201027$ end

$101.00 \mathrm{e}-201027$ end

$101.00 e-201027$ end

$101.00 e-201027$ end

$101.00 \mathrm{e}-201027$ end

$101.00 \mathrm{e}-201027$ end

$1001.00 e-201027$ end

$101.00 \mathrm{e}-201027$ end

$101.00 e-201027$ end

$10.1 .00 e-201027$ end

$101.00 e-201027$ end

$101.00 e-201027$ end

$101.00 \mathrm{e}-20 \quad 1027$ end

$101.00 e-201027$ end

$101.00 e-201027$ end

$101.00 e-201027$ end

$101.00 e-20 \quad 1027$ end

$101.00 \mathrm{e}-201027$ end

$101.00 \mathrm{e}-20 \quad 1027$ end

$101.00 \mathrm{e}-201027$ end

$101.00 \mathrm{e}-20 \quad 1027$ end

$1001.00 e-201027$ end

$101.00 e-201027$ end

$101,00 \mathrm{e}-201027 \cdot$ end

$101,00 e-201027$ end

$1001.00 \mathrm{e}-201027$ end

$101.00 \mathrm{e}-201027$ end

$101.00 e-201027$ end

$101.00 e-201027$ end

$101.00 e-201027$ end

$1001.00 e-201027$ end

$101.00 \mathrm{e}-201027$ end

$101.00 e-201027$ end

$101.00 e-201027$ end

$1001.00 e-201027$ end

$101.00 e-201027$ end

$101.00 \mathrm{e}-201027$ end

$101.00 e-201027$ end

$101.00 e-201027$ end

$101.00 \mathrm{e}-201027$ end

$101.00 e-201027$ end

$1001.00 e-20 \quad 1027$ end

$101.00 \mathrm{e}-20 \quad 1027$ end

$101.00 e-201027$ end

$101.00 e-201027$ end

$101.00 e-201027$ end

$101.00 e-201027$ end

$101.00 e-20 \quad 1027$ end

$101.00 e-201027$ end

$101.00 e-201027$ end

$101.00 e-201027$ end

$101.00 \mathrm{e}-201027$ end

$1001.00 e-20 \quad 1027$ end

$101.00 e-201027$ end

$101.00 e-201027$ end

$101.00 \mathrm{e}-201027$ end

$101.00 \mathrm{e}-201027$ end 
te-128 $\quad 101.00 e-201027$ end $x e-128 \quad 101.00 e-201027$ end te $-129 \mathrm{~m}$ i $0.1 .00 \mathrm{e}-20 \quad 1027$ end $i-129 \because 1001.00 e-201027$ end $x e-129 \quad 101.00 e-201027$ end te-130 10 1.00e-20 1027 end $i-130 \quad 101.00 e-201027$ end xe-130 10 1.00e-20 1027 end i-131 10 l.00e-20 1027 end $x e-131 \quad 101.00 e-201027$ end te-132 $1001.00 e-201027$ end xe-132 10 1.00e-20 1027 end $x e-133 \quad 1 \quad 0 \quad 1.00 e-201027$ end cs-133 $101.00 e-201027$ end $x e-134 \quad 1001.00 e-201027$ end cs-134 $101.00 \mathrm{e}-201027$ end ba-134 $1001.00 e-201027$ end $i-135 \quad 101.00 e-201027$ end cs-135 $1001.00 \mathrm{e}-201027$ end ba-135 $101.00 e-201027$ end $\mathrm{xe}-136 \quad 1001.00 \mathrm{e}-201027$ end cs-136 $1001.00 e-201027$ end ba-136 $1001.00 \mathrm{e}-201027$ end cs-137 $101.00 \mathrm{e}-201027$ end ba-137 $1001.00 e-201027$ end ba-138 $1001.00 \mathrm{e}-201027$ end $1 a-139 \quad 101.00 \mathrm{e}-201027$ end ba-140 $1001.00 e-201027$ end $1 a-140 \quad 1001.00 e-201027$ end ce-140 $101.00 e-201027$ end ce-141 10 1.00e-20 1027 end pr-141 $1001.00 e-201027$ end ce-142 $1001.00 \mathrm{e}-201027$ end pr-142 I $011.00 \mathrm{e}-201027$ end nd-142 10 1.00e-20 1027 end $\mathrm{ce}-143 \quad 1 \quad 0 \quad 1.00 \mathrm{e}-201027$ end pr-143 $1001.00 \mathrm{e}-201027$ end nd-143 $1001.00 e-201027$ end ce-144 $1001.00 e-201027$ end nd-144 $1001.00 e-201027$ end nd-145 10 1.00e-20 1027 end nd-146 $1001.00 e-201027$ end nd-147 $1001.00 \mathrm{e}-201027$ end pm-147 $1001.00 e-201027$ end sm-147 10 1.00e-20 1027 end nd-148 $1001.00 e-201027$ end pm-148 $1001.00 e-201027$ end pm-148m $101.00 \mathrm{e}-201027$ end sm-148 $10.1 .00 e-201027$ end pm-149 $1001.00 e-201027$ end nd-150 $1001.00 e-201027$ end sm-150 10 1.00e-20 1027 end pm-151 $1001.00 \mathrm{e}-201027$ end sm-151 $101.00 e-201027$ end eu-151 10 1.00e-20 1027 end sm-152 $1001.00 e-201027$ end eu-152 $101.00 \mathrm{e}-201027$ end gd-152 $1001.00 e-201027$ end sm-153 10 1.00e-20 1027 end eu-153 - $101.00 e-201027$ end sm-154 $1001.00 e-201027$ end eu-154 $101.00 e-201027$ end gd-154 $1001.00 e-201027$ end eu-155 $1001.00 e-201027$ end gd-155 $1001.00 e-201027$ end eu-156 $1001.00 \mathrm{e}-201027$ end gd-156 $1001.00 e-201027$ end eu-157 $1001.00 e-201027$ end gd-157 $1001.00 e-201027$ end gd-158 $101.00 e-201027$ end tb-159 $1001.00 e-201027$ end gd-160 $101.00 e-201027$ end tb-160 $1001.00 e-201027$ end $d y-160 \quad 1 \quad 0 \quad 1.00 e-201027$ end $d y-161 \quad 101.00 e-201027$ end $d y-162 \quad 1 \quad 0 \quad 1.00 e-20 \quad 1027$ end dy-163 $1001.00 \mathrm{e}-201027$ end $\mathrm{dy}-164 \quad 1 \quad 0 \quad 1.00 \mathrm{e}-201027$ end ho-165 10 1.00e-20 1027 end er-166 $101.00 \mathrm{e}-201027$ end er-167 $101.00 e-201027$ end $\checkmark$ end of fission products

$\begin{array}{llllll}\mathrm{zr} & 2 & 0 & 4.23-2 & 579 & \text { end } \\ \mathrm{h} & 3 & 0 & 4.783-2 & 579 & \text { end } \\ 0-16 & 3 & 0 & 2.391-2 & 579 & \text { end } \\ \mathrm{b}-10 & 3 & 0 & 4.7344-6 & 579 & \text { end } \\ \mathrm{b}-11 & 3 & 0 & 1.9177-5 & 579 \text { end }\end{array}$

end comp

fuel-pin-cell geometry:

triangpitch $1.275 \quad 0.772130 .91642$ end

more data $d z=0 . d y=57.357 \quad b k l=0.0$ szf $=.75$ isn $=16$

eps $=.00001$ ptc $=.00001$ end

assembly and cycle parameters:

$\mathrm{npin} / \mathrm{assm}=1$ fuelngth $=223.66843$

ncycles $=32 \mathrm{nlib} / \mathrm{cyc}=1$

printlevel $=6$

lightel $=1$

power $=.0340078$ burn $=0.00001$ down $=0$ end power $=.0340078$ burn $=29.40502$ down $=0$ end power $=.0340078$ burn $=58.81004$ down $=0$ end power $=.0340078$ burn $=58.81004$ down $=0$ end power $=.0340078$ burn $=58.81004$ down $=0$ end power $=.0340078$ burn=58.81004 down $=0$ end power $=.0340078$ burn $=58.81004$ down $=0$ end power $=.0340078$ burn $=58.81004$ down $=0$ end power $=.0340078$ burn $=58.81004$ down $=0$ end power $=.0340078$ burn $=58.81004$ down $=0$ end power $=.0340078$ burn $=58.81004$ down $=0$ end power $=.0340078$ burn $=58.81004$ down $=0$ end power $=.0340078$ burn $=58.81004$ down $=0$ end power $=.0340078$ burn $=58.81004$ down $=0$ end power $=.0340078$ burn $=58.81004$ down $=0$ end power $=.0340078$ burn $=58.81004$ down $=0$ end power $=.0340078$ burn $=58.81004$ down $=0$ end power $=.0340078$ burn $=58.81004$ down $=0$ end power $=.0340078$ burn $=58.81004$ down $=0$ end power $=.0340078$ burn $=58.81004$ down $=0$ end power $=.0340078$ burn $=58.81004$ down $=0$ end power $=.0340078$ burn $=58.81004$ down $=0$ end power $=.0340078$ burn $=58.81004$ down $=0$ end power $=.0340078$ burn $=58.81004$ down $=0$ end power $=.0340078$ burn $=58.81004$ down $=0$ end power $=.0340078$ burn $=58.81004$ down $=0$ end power $=.0340078$ burn $=58.81004$ down $=0$ end power $=.0340078$ burn $=58.81004$ down $=0$ end power $=.0340078$ burn $=58.81004$ down $=0$ end power $=.0340078$ burn $=58.81004$ down $=0$ end power $=.0340078$ burn $=58.81004$ down $=0$ end power $=.0340078$ burn $=58.81004$ down $=0$ end zr $\quad 0.27444$

end 


\section{INTERNAL DISTRIBUTION}

1. B. B. Bevard

2. S.M. Bowman

3. B.L. Broadhead

4. J.J. Carbajo

5. R.L. Childs

6. E.D. Collins

7. B.S. Cowell

8. M.D. DeHart

9. F.C. Difilippo

10. K.R. Elam

11-15. R.J. Ellis

16. M.B. Emmett

17. P.B. Fox

18. I.C. Gauld

19. J.C. Gehin

20. S.R. Greene

21. O.W. Hermann

22. R. Holdaway

23. D.F. Hollenbach

24. T.W. Horning

25. D.T. Ingersoll
26. H.T. Kerr

27. R.A. Lillie

28. M.A. Kuliasha

29. S. Ludwig

30. G.E. Michaels

31. D.L. Moses

32. B.D. Murphy

33. C.V. Parks

34. L.M. Petrie

35. R.T. Primm III

36. W.J. Reich

37. C.H. Shappert

38. C.C. Southmayd

39. D. Spellman

40. J.C. Wagner

41. R.M. Westfall

42. G.L. Yoder, Jr.

43. Central Research Library

44-45. ORNL Laboratory Records for submission to OSTI

46. ORNL Laboratory Records - RC

\section{EXTERNAL DISTRIBUTION}

47. M.L. Adams, Department of Nuclear Engineering, Texas A\&M University, Zachry 129, College Station, TX 77843

48. D. Alberstein, Los Alamos National Laboratory, MS-E502, P.O. Box 1663, Los Alamos, NM 87545

49. J.F. Baker, Office of Fissile Materials Disposition, U.S. Department of Energy, MD-3, 1000 Independence Avenue SW, Washington, DC 20585

50. J.B. Briggs, Idaho National Environmental and Engineering Laboratory, P.O. Box 1625-3855, Idaho Falls, ID 83415-3855 
51. M.S. Chatterton, U.S. Nuclear Regulatory Commission, Office of Nuclear Reactor Regulation, MS O10 B3, Washington, DC 20555-0001

52. K. Chidester, Los Alamos National Laboratory, MS-E502, P.O. Box 1663, Los Alamos, NM 87545

53. R.H. Clark, Duke Cogema Stone \& Weber, 400 South Tyrone Street, WC-32G, P.O. Box 1004, Charlotte, NC 28202

54. W. Danker, U.S. Department of Energy, MD-3, 1000 Independence Avenue SW, Washington, DC 20585

55. C. Dourougie, 5 Allee Andre Malraux, 91330 Yerres, France

56. N. Fletcher, Office of Fissile Materials Disposition, U.S. Department of Energy, MD-3, 1000 Independence Avenue SW, Washington, DC 20585

57. T. Gould, Lawrence Livermore National Laboratory, P.O. Box 808, MS-L186, Livermore, CA 94551

58. L. Holgate, Office of Fissile Materials Disposition, U.S. Department of Energy, MD-1/2, 1000 Independence Avenue SW, Washington, DC 20585

59. L. Jardine, Lawrence Livermore National Laboratory, P.O. Box 808 , MS-L166, Livermore, CA 94551

60-64. A. Kalashnikov, Institute of Physics and Power Engineering, 1 Bondarenko Square, Obninsk, Kaluga Region, Russia 249020

65. M.A. Kalugin, Russian Research Center - "Kurchatov Institute", Institute of Nuclear Reactors, VVER Division, VVER Physics Department, 123182, Kurchatov Square, 1, Moscow, Russia

66. D.E. Klein, Associate Vice Chancellor for Special Engineering Programs, The University of Texas System, 210 West Sixth Street, Austin, TX 78701

67. J. Nesbit, Duke Cogema Stone \& Weber, 400 South Tyrone Street, WC-32G, P.O. Box 1004, Charlotte, NC 28202

68. J.O. Nulton, Office of Fissile Materials Disposition, U.S. Department of Energy, MD-3, 1000 Independence Avenue SW, Washington, DC 20585

69. Office of the Assistant Manager for Energy Research and Development, U.S. Department of Energy, Oak Ridge Operations (DOE-ORO), P.O. Box 2008, Oak Ridge, TN 37831

70. S.L. Passman, Sandia National Laboratories, Suite 110, 950 L'Enfant Plaza SW, Washington, DC 20024-2123

71-75. A. Pavlovitchev, Russian Research Center - "Kurchatov Institute", Institute of Nuclear Reactors, VVER Division, VVER Physics Department, 123182, Kurchatov Square, 1, Moscow, Russia

76. K.L. Peddicord, Associate Vice Chancellor, Texas A\&M University, 120 Zachry, College Station, TX 77843-3133

77. G. Radulescu, Framatom Cogema Fuels, 1261 Town Center Drive, MS-423, Las Vegas, Nevada 89143 
78. W.D. Reece, Texas A\&M University, Department of Nuclear Engineering, Zachry 129, College Station, TX 77843-3133

79. P.T. Rhoads, Office of Fissile Materials Disposition, U.S. Department of Energy, MD-4, 1000 Independence Avenue SW, Washington, DC 20585

80. E. Sartori, OECD/NEA Data Bank, 12 Bd des Iles, 92130 Issy-les-Moulineaux, France.

81. J. Thompson, Office of Fissile Materials Disposition, U.S. Department of Energy, MD-4, 1000 Independence Avenue SW, Washington, DC 20585

82. U. Shoop, U.S. Nuclear Regulatory Commission, Office of Nuclear Reactor Regulation, MS O10 B3, Washington, DC 20555-0001

83. M. Williams, Louisiana State University, Baton Rouge, LA 70803-5820 